\title{
Temporal Changes in Key Signal Transduction Pathways Mediating Muscle Protein Synthesis with Adaptive and Maladaptive Right Ventricular Hypertrophy in Pulmonary Arterial Hypertension
}

\section{Ryan Middleton}

University of California, San Diego https://orcid.org/0000-0002-1293-5896

Mario Fournier

Cedars-Sinai Heart Institute

Russell Rogers

Cedars-Sinai Heart Institute

Brandon Grimes

University of California Los Angeles

\section{Xuan Xu}

Cedars-Sinai Heart Institute

Michael Lewis ( $\nabla$ Michael.Lewis@cshs.org )

Cedars-Sinai Health System https://orcid.org/0000-0001-9600-2438

\section{Research Article}

Keywords: Muscle Protein, Ventricular Hypertrophy, Pulmonary Arterial

Posted Date: December 10th, 2021

DOl: https://doi.org/10.21203/rs.3.rs-1047703/v1

License: (c) (i) This work is licensed under a Creative Commons Attribution 4.0 International License.

Read Full License 


\section{Abstract}

\section{Background}

Pulmonary Arterial Hypertension (PAH) is a progressive cardiopulmonary disease and is characterized by occlusive remodeling of pulmonary arterioles and increased pulmonary vascular resistance. With the onset of PAH, the right ventricle (RV) of the heart adapts to the increased afterload pressure by undergoing adaptive hypertrophic remodeling to maintain adequate blood flow. However, for unknown reasons, maladaptive influences ensue, resulting in impaired RV function with progressive decompensation and right heart failure. Using a rodent model of PAH, we evaluated key signaling pathways mediating cardiac muscle protein synthesis in the RV during the adaptive hypertrophy phase, with preserved right heart function, and the decompensated maladaptive phase, in which right heart failure (RHF) was clinically present.

Methods

Male Sprague-Dawley rats were injected subcutaneously with $60 \mathrm{mg} / \mathrm{kg}$ Monocrotaline (MCT) and RV function was assessed by echocardiography during PAH disease progression. RV tissue was collected during the adaptive and maladaptive phases of PAH and cell signaling pathways involved in survival, hypertrophy, and autophagy, as well as fibrosis and vascularization, were probed using qPCR, Western blotting and histology. Statistical analysis was performed using ANOVA to compare differences between the independent groups and Student-Newman-Keuls test was used to compare differences within independent groups.

\section{Results}

Analysis of protein and gene expression changes in PAH animals identified three key signaling pathways involved in the shift toward maladaptive right heart failure: i) PI3K/Akt/mTOR; ii) GSK-3; iii) MAPK/ERK, as well as IGF-1 regulation. During adaptive hypertrophy, significant increments of phosphorylated proteins in the three signaling pathways were observed with increases in RV fibrosis and decreased capillarity found. In the maladaptive phase, $\mathrm{mTORC} 1$ and its downstream effector $\mathrm{p}-70^{\mathrm{S} 6 \mathrm{~K}}$ were significantly activated, contributing to the decreased LC3-I/II ratio, a marker of autophagy inhibition. Additionally, p27, a cyclin-dependent kinase (CDK) inhibitor, which has been recently implicated in regulating mTOR activity to inhibit autophagy and promote heart failure was significantly downregulated.

\section{Conclusion}

We propose that autophagy inhibition in conjunction with other maladaptive processes reported in the decompensated RV muscle contributes to the genesis of overt RHF in PAH and that a continuum of changes characterizes the adaptive and maladaptive phases in the RV muscle.

\section{Background}


Pulmonary arterial hypertension (PAH) is a progressive condition for which there is no cure. Even with substantial pharmacologic advances in the modern treatment era, survival remains unacceptably poor [13]. PAH is characterized by occlusive remodeling of pulmonary arterioles and increased pulmonary vascular resistance. With the onset of PAH, the right ventricle (RV) adapts to the increased afterload presented to it by adaptive hypertrophy to maintain adequate blood flow. This is driven by signaling events that promote enhanced muscle protein synthesis and physiologic growth. However, for unknown reasons, maladaptive influences ensue, resulting in impaired RV function with progressive decompensation and failure [4]. Indeed, RV function is the major factor determining survival of patients with PAH [5-8].

We and others have reported that several signaling pathways involved in muscle protein synthesis are important mediators of adaptive cardiac and skeletal muscle hypertrophy. This includes the phosphatidylinositol 3-kinase (PI3K)/Akt/mammalian target of rapamycin (mTOR) pathway, as a major regulator of cardiac and skeletal muscle protein synthesis and hypertrophy [9-14], with significant depression in the diaphragm muscle in atrophic states [15]. Another signaling pathway mediating enhanced cardiac muscle protein synthesis and growth, is the glycogen synthase kinase-3 (GSK-3) pathway which plays a key role in the integration of hypertrophic signaling in the heart, involving both a and $\beta$ isoforms $[16,17]$. Lastly, the mitogen-activated protein kinases (MAPK)/extracellular signalregulated kinases (ERK) 1/2 pathways also exhibit significant influences in promoting cardiomyocyte hypertrophy $[15,18-20]$.

We postulate that these three signaling pathways would be key in mediating adaptive changes in the RV muscle exposed to a slow progressive rise in RV afterload facing the RV as PAH develops. We thus studied the temporal changes in signaling of these three pathways as PAH develops in an animal model of $\mathrm{PAH}$, for which there are limited data. In addition, we serially evaluated insulin like growth factor-1 (IGF-1) as this growth factor has been shown to both impact upon these three pathways [21] and has been implicated in reports of physiologic cardiac hypertrophy [10, 22-24]. Further, we also evaluated the expression of proteins related to these three signaling pathways together with IGF-1 levels in the decompensated maladapted RV muscle of rats with established right ventricular dysfunction and failure. The latter was confirmed by echocardiographic parameters of impaired RV systolic function along with confirmatory changes at the cellular level, which included changes in RV wall fibrosis and capillarity.

In the monocrotaline (MCT) rat model of PAH, our observations in both the adapted and maladapted states describe several directions of change in the RV muscle that were unanticipated based on skeletal muscle data [15] and provide robust data and important questions for future research endeavors in fully understanding RV physiologic and pathobiologic changes that occur in the RV with progressive $\mathrm{PAH}$. We also demonstrate in several instances, a continuum of changes as progression from an apparent adaptive state evolves into a full-blown maladaptive milieu.

\section{Methods}




\section{Animals}

Adult male Sprague-Dawley rats (initial body weight $\sim 225 \mathrm{~g} ; \mathrm{n}=52$ ) were divided into 2 major groups, namely control (CTL) and PAH. The CTL rats were injected subcutaneously with saline, while the PAH animals received a single subcutaneous injection of MCT (Sigma, St. Louis, MO) at a dose of $60 \mathrm{mg} / \mathrm{kg}$ body weight, dissolved in $0.5 \mathrm{~mL}$ saline. All animals were provided with food (Purina rat chow) and water ad libitum. Animals were individually housed with a dark: light cycle of 12 hours each and with the ambient temperature maintained at $22^{\circ} \mathrm{C}$. Terminal experiments were performed at days $7,14,24$ and 28 (adapted cohort) and at 28 or more days (maladapted cohort, based on echocardiography).

\section{Cardiac Muscle Weights and Measurement of RV pressures}

The animals were anesthetized with either a combination of ketamine $(100 \mathrm{mg} / \mathrm{kg})$ and xylazine (10 $\mathrm{mg} / \mathrm{kg}$ ) injected intraperitoneally or with inhalational isoflurane. The right external jugular vein was exposed via a minor surgical cut-down and the vein cannulated with a 1.4F Mikro-Tip catheter pressure transducer (SPR-671; Millar Instruments, Houston, TX). The catheter was advanced into the RV with measurements of RV systolic pressure via a dual channel pressure control unit (PCU-2000; Millar Instruments). Pressures were monitored and stored for later analysis using a PowerLab 8/30 (ML870) data acquisition system ( $A D$ Instruments, Colorado Springs, $C O$ ) connected to an IBM ThinkPad computer with LabChart 7 Pro data acquisition and analysis software (v7.2; AD Instruments). Subsequently the heart was excised, and the RV wall was separated from the left ventricle (LV) and the interventricular septum (S) using a dissecting microscope and their weights recorded. Both the RV mass and the ratio of $R V / L V+S$ were used as indices of RV hypertrophy.

\section{Echocardiography}

Transthoracic two-dimensional, M-mode echocardiography and pulsed-wave Doppler imaging were performed on anesthetized (isoflurane) rats (Vevo 770 Micro-Ultrasound imaging system; Visual Sonics: Toronto, Canada). RV systolic function was determined by tricuspid annular plane systolic excursion (TAPSE), recorded in M-mode. Doppler of pulmonary outflow measured pulmonary artery flow velocity time (PA VTI). To obtain stroke volume (SV), the cross-sectional area of the pulmonary artery was multiplied by PA VTI, and estimated cardiac output (CO) was derived by multiplying SV by heart rate. Serial studies were performed before and post MCT administration.

\section{Muscle Proteins}

Protein extraction: RV muscle segments were rapidly frozen in liquid nitrogen and stored at $-80^{\circ} \mathrm{C}$ until analysis. Sample protein was extracted in a 1:10 ratio of cold RIPA buffer (Cell Signaling Technologies, Beverly, MA), with protease and phosphatase inhibitors (Roche, South San Francisco, CA) added, according to manufacturer's protocol. For mTOR analysis samples, $0.4 \%$ CHAPS was also added to the lysis buffer. Homogenization was performed with a Polytron homogenizer (Kinematica, Bohemia, NY) and tissue lysates were incubated on ice for 4 hours and then were centrifuged at 13,200 RPM. The 
supernatant was aliquoted in microcentrifuge tubes. Protein concentration was determined using a commercial protein assay kit (Bio-Rad, Hercules, CA) and measured with a spectrophotometer (SmartSpecä 3000, Bio-Rad).

Immunoprecipitation: For mTOR analysis only, protein lysates were precleared with normal IgG (Santa Cruz Biotechnology, Dallas, TX) and protein A/G Plus-agarose beads (Santa Cruz Biotechnology). The lysates were incubated with the primary antibody (mTOR or phosphorylated mTOR $\left(\operatorname{Ser}^{2448}\right.$ ); Cell Signaling Technology, Beverly, MA) overnight at $4^{\circ} \mathrm{C}$. Protein A/G Plus-agarose beads were added to the immunocomplex, incubated for 4 hours at $4^{\circ} \mathrm{C}$, and centrifuged. The immunocomplex pellet was washed, resuspended in sample buffer, heated at $70^{\circ} \mathrm{C}$ for $15 \mathrm{~min}$ and centrifuged. The supernatant was used to load gels for electrophoresis as described below.

SDS-PAGE and Western blotting: Electrophoresis of protein extracts was performed by SDS-PAGE. In brief, samples were heated at $70^{\circ} \mathrm{C}$ for $15 \mathrm{~min}$ and cooled prior to being used for electrophoresis. Protein extracts (40 mg per well) were loaded on NuPAGE 4-12\% Bis-Tris gradient gels (Invitrogen, Grand Island, NY). For the analysis of 4E-BP1 (PHAS-I) samples, extracts were loaded on 12\% Bis-Tris gels. Separated proteins were then electrophoretically transferred to nitrocellulose membranes (Bio-Rad). The membranes were treated with blocking buffer for 1 hour at room temperature. Blots were incubated with primary antibodies at $4^{\circ} \mathrm{C}$ overnight, washed and incubated with an appropriate peroxidase-conjugated secondary antibody at room temperature for 1 hour. The blots were visualized following development with enhanced chemiluminescence (ECL) Western blotting detection reagents (GE Healthcare Life Sciences, Pittsburgh, PA), according to manufacturer's protocol. Blots were re-used by exposing them to stripping buffer (Restoreä, Thermo Scientific, Rockford, IL) and re-probed with a different primary antibody to enable direct comparison of phosphorylated and non-phosphorylated states. Blots were exposed to X-ray film in a cassette, the films scanned, and identified bands analyzed by densitometry using Image $1.43 \mathrm{u}(\mathrm{NIH})$. Western blot data from the experimental groups were expressed relative to measured mean values from the CTL group. All results are expressed as the ratio of phosphorylated protein/total protein.

Primary antibodies: All primary antibodies were rabbit polyclonal antibodies obtained from Cell Signaling Technology, except for phosphospecific 4E-BP1 (Bethyl Laboratories, Montgomery, TX) and mouse monoclonal antibody for total GSK-3 (Santa Cruz Biotechnology). Blots were first incubated with the following anti-phosphopeptide (P) antibodies: P-Akt $\left(\mathrm{Ser}^{473}\right), \mathrm{P}-\mathrm{p} 70^{\mathrm{S} 6 \mathrm{~K}}\left(\mathrm{Thr}^{389}\right), \mathrm{P}-\mathrm{GSK}-3 \mathrm{a} / \mathrm{b}\left(\mathrm{Ser}^{21 / 9}\right)$, PERK1/2 (p44/p42) (Thr ${ }^{202} /$ Tyr $\left.^{204}\right)$, P-mTOR (Ser $\left.{ }^{2448}\right)$, P-CDK2 (Thr $\left.{ }^{160}\right)$, and P-4E-BP1 (PHAS-I). Stripped membranes were re-probed with antibodies recognizing total Akt, p70 ${ }^{\mathrm{S} 6 \mathrm{~K}}, \mathrm{GSK}-3 \mathrm{a} / \mathrm{b}, \mathrm{ERK} 1 / 2$ (p44/p42), mTOR, CDK2, 4E-BP1 as well as GAPDH, with the latter serving as a control for equal protein loading of samples. Blots to probe for non-phosphopeptide proteins were first incubated with $\mathrm{p} 27$, or LC3B antibodies.

IGF-1 protein measurement by ELISA: Determination of IGF-1 in the adaptive hypertrophy experiments was performed as previously described [25]. Briefly, frozen RV muscle segments were pulverized in liquid nitrogen. Protein was extracted twice on cold acetic acid $(1 \mathrm{M} ; 1 \mathrm{mg} / 10 \mu \mathrm{l})$ and supernatant stored at 
$-80^{\circ} \mathrm{C}$ overnight. Aliquots $(100 \mu \mathrm{l})$ were lyophilized and stored frozen overnight. Protein pellets were resuspended in $40 \mu \mathrm{I} \mathrm{H}_{2} \mathrm{O}$ and protein concentration determined as described above. Duplicate $10 \mu \mathrm{l}$ protein samples were assayed using a commercial high sensitivity ELISA kit for rodent IGF-1 (AC-42F1) from Immunodiagnostic Systems, Inc. (IDS; Gaithersburg, MD) according to manufacturer's protocol.

Note, for the maladapted RV muscle IGF-1 assays a different kit was used, as the Immunodiagnostic Systems kit (AC-42F1) had been discontinued. Thus, for these experiments, we used a rat IGF-1 ELISA Kit (Catalog \# 80573) from Crystal Chem (Elk Grove Village, IL). Results are expressed as ng/ mg protein.

\section{RNA Extraction and Quantitative Polymerase Chain Reaction (qPCR)}

Total RNA extraction: Total RNA was extracted from RV muscle segments with RNeasy Mini Kit (Qiagen, Valencia, CA) according to manufacturer's protocol. RNA concentration was measured with a spectrophotometer (NanoDrop 1000; Thermo Scientific).

2.4.2 Oligonucleotides: The primers for IGF-1Ea and the reference gene succinate dehydrogenase A (SDHA) were designed based on published rat cDNA sequences. Sequences of primers used for CDNA synthesis and RT-qPCR analysis, along with their accession number were the following: IGF-1Ea (NM_001082478): Forward 5'-GCTTGCTCACCTTTACCAGC-3', Reverse 5'-AAATGTACTTCCTTCTGAGTCT3'; SDH-A (NM_130428): Forward 5'-CTCTTTTGGACCTTGTCGTCTTT-3', Reverse 5'TCTCCAGCATTTGCCTTAATCGG-3'.

Real-time quantitative PCR: RT-qPCR was performed in two steps. One ug of total RNA per sample was reverse transcribed with Superscript III using Oligo (dT) 20 (Invitrogen) according to manufacturer's protocol. qPCR was performed in 10 ul reactions using 2X Sybr Green Master Mix (ABi P/N 4309155), 50 $\mathrm{nM}$ gene specific primers, and $2 \mathrm{ul}$ of the reverse transcribed samples. Samples were analyzed in triplicates across the genes on the ABi Viia7. In order to compare the relative mRNA expression between control and experimental groups, the comparative threshold cycle $\left(\mathrm{C}_{\mathrm{T}}\right.$; the fractional cycle number at which the amount of amplified target reaches a fixed threshold) method was used.

\section{Histological Studies}

Fibrosis: To assess fibrosis, cryosections of RV free wall from 5 adapted, 5 maladapted and 3 CTL rats were stained with Picrosirius Red as described $[26,27]$. Sections were imaged by brightfield microscopy and analysis was performed using ImageJ (Fiji), by measuring pixel density within the green channel throughout the entire RV free wall $[28,29]$. One section was analyzed for each animal and normalized to the total area of the RV free wall. Results are presented as percent fibrosis.

Vessel counts: To assess vascularity in CTL, adapted and maladapted RV free wall from PAH animals, $10 \mu \mathrm{m}$ tissue sections were stained with anti-rat smooth muscle actin primary antibody (1:100, Sigma ) and FITC-conjugated goat anti-rat secondary antibody (1:400, Abcam), and TRITC conjugated isolectin 
IB4 (Thermo). The stained tissue sections were imaged by confocal microscopy (Leica) and analyzed using ImageJ (Fiji). 10 cryosections were analyzed per animal.

\section{Statistical Analysis}

The distribution of all data was tested for normality and then statistical analysis was performed using ANOVA (Instat v. 3.06, GraphPad, San Diego, CA) to compare differences between the independent groups in the adaptive state study. If a significant interaction was found, post hoc analysis (Student-NewmanKeuls test) was used to compare differences within independent groups. A Student t-test was used to compare differences between the groups in the maladaptive state study. An a level of 0.05 was used to compare differences in independent groups and to determine overall significance. Values are expressed as means $\pm \mathrm{SEM}$.

\section{Results}

\section{ADAPTIVE RV HYPERTROPHY}

\section{Animal Weights and RV Pressures}

During the RV adaptive phase of PAH, there was a progressive increment in CTL body weight, as expected. No difference in body weight was observed at day 7 between CTL and PAH rats. At days 14, 24 and 28 body weight gains were attenuated by $6,8 \%$ and $21 \%$ respectively, for $\mathrm{PAH}$ animals compared to $C T L(P<0.01$; Figure 1). An assessment of RV systolic pressures found similar pressures between CTL and PAH animals at day 7. Thereafter, a significant and progressive rise in RV pressures was observed in PAH rats at days 14, 24 and $28(1.9,2.6$ and 2.8-fold-increment respectively; $P<0.001)$ compared with CTL animals $(P<0.001)$. RV systolic pressures of PAH rats at days 24 and 28 were not significantly different. [see Supplemental figure $1 \mathrm{~A}$ in ref. 30].

\section{Indices of RV Hypertrophy}

$\mathrm{RV}$ mass and the ratio of RV/LV+S were similar between the CTL and PAH rats at days 7 and 14 , indicating no RV hypertrophy at these times, despite significantly increased RV pressures at day 14 . Significant RV hypertrophy however was evident at day 24 , with RV mass 1.6 -fold larger than CTL $(P<$ $0.001)$ and the RV/LV+S index increased by 1.8 -fold $(P<0.001)$. At day 28 , RV mass was increased by by 1.8-fold $(P<0.001)$ and RV/LV+S index by 2.2-fold $(P<0.001$; [see Supplemental figure 1B in ref. 30].

\section{Echocardiography}

TAPSE, a measure of RV systolic function, was measured in MCT rats and compared to CTL animals. No significant differences were observed between CTL rats and PAH animals 28 days post MCT administration. (CTL: 2.9 +/- 0.7 mm; PAH: 2.8 +/- $0.14 \mathrm{~mm}$ ). 
Estimated $\mathrm{CO}$ for $\mathrm{PAH}$ rats all time frames during the compensatory period were not significantly different from CTL values, and so the data was pooled for PAH animals (CTL: 124 +/- $8 \mathrm{ml} / \mathrm{min}$; PAH: 100 +/- 4 $\mathrm{ml} / \mathrm{min}$ ). Values for $\mathrm{CO}$ for CTL rats were similar to those previously reported for male Sprague-Dawley rats of the same weight range [31].

\section{Signaling Data}

For all protein studies in the RV muscle, phosphorylated proteins are expressed as the ratio of phosphorylated $(\mathrm{P})$ protein/total protein.

\section{PI3K/Akt/mTOR pathway:}

Phosphorylated Akt, mTOR and down steam effectors, 4E-BP1 and $\mathrm{p} 70^{\mathrm{S} 6 \mathrm{~K}}$ were analyzed. As noted in Figure 2A, P-Akt and P-mTOR were not significantly different between CTL and PAH rats at days 7 and 14 . However, significant increments for both signaling proteins were observed at day 24 in PAH animals compared to CTL (1.3 and 1.4-fold increment respectively; $\mathrm{P}<0.05$ and $\mathrm{P}<0.01$; Figure 2A). At day 28 , levels of P-Akt and P-mTOR had returned to control levels.

The downstream effector P-p70 $56 \mathrm{~K}$ was unchanged at days 7 and 14 in PAH rats, but significantly elevated at days 24 and 28 compared to CTL ( 1.6 and 2.4-fold increments respectively; $P<0.01$ and $P<$ 0.001; Figure 2B). The hyperphosphorylated $y$ form of 4E-BP1 was significantly elevated only at days 24 and 28 in PAH rats compared to CTL by 1.7 and 1.2-fold respectively $(P<0.001$ and $P<0.05$; Figure 2B). The ratio of $y / a+\beta+\gamma$ was increased only at day $24(P<0.05$; not shown).

\section{GSK-3 pathway:}

Both P-GSK-3a and P-GSK-3 $\beta$ were assayed. For both P-GSK-3a and $\beta$, values at days 7 and 14 were similar between CTL and PAH rats (Figure 3A). However, both P-GSK-3a and $\beta$ were significantly increased by 1.4 and 1.3-fold respectively in PAH rats at day 24 respectively $(P<0.001$ and $P<0.001)$. At day 28 P-GSK-3a had returned to CTL levels, while P-GSK-3 $\beta$ was significantly reduced $(P<0.05$; Figure $3 A)$.

\section{MAPK/ERK pathway:}

Both P-p44 (ERK1) and P-p42 (ERK2) were assayed. Values for both P-p44 and P-p42 were similar between CTL and PAH rats at days 7 and 14 (Figure 3B). At day 24 however, significant increments were observed for both P-p44 (1.6-fold; P < 0.001) and P-p42 (1.4-fold; P < 0.05) in PAH rats compared to CTL. At day 28 P-p44 values were still 16\% greater than CTL (NS), while P-p42 expression had returned to CTL values (Figure 3B).

\section{IGF-1 mRNA}


The abundance of IGF-1 mRNA in RV muscle tended to increase 1.47 and 2-fold in PAH rats at days 7 and 14 respectively compared with CTL (NS; Figure 4). However, IGF-1 mRNA levels rose significantly at days 24 (6.5-fold; $\mathrm{P}<0.05$ ) and 28 (7.4-fold; $\mathrm{P}<0.01$ ) in PAH rats compared to CTL (Figure 4).

\section{IGF-1 Protein Assays}

IGF-1 protein expression in the RV muscle of PAH rats were similar to that in CTL animals between days 7and 24 (Figure 4). At day 28 a significant $45 \%$ reduction $(P<0.001)$ in IGF-1 expression in the RV of PAH rats was noted compared to CTL (Figure 4).

\section{MALADAPTIVE RV and Right Heart Failure}

\section{Animal Weights and RV Pressures}

PAH rats were also studied 28 or more days post MCT administration until they develop RHF. During this period there was significant weight loss from peak weight achieved over time to weight at the time of terminal experiments (Peak weight: $362+/-3 \mathrm{~g}$; Terminal weight: $299+/-11 \mathrm{~g}$; $\mathrm{P}<0.01$ ). In addition, other observational signs suggestive of right heart failure were evident. This included a progressive listless state with obvious reduced mobility, poor grooming and ruffled fur and tachypnea with a pattern of increased work of breathing. Abdominal distension suggested the presence of ascites. Animals were sacrificed at this point, which was a joint decision by the investigators and veterinary staff. Post sacrifice, the presence of ascites +/- pleural effusions were confirmed.

\section{Echocardiography}

Mean value of TAPSE for this maladapted PAH cohort was significantly reduced compared to CTL and other adapted PAH animals $(1.73+/-0.144 \mathrm{~mm} ; \mathrm{P}<0.01$; Figure 5A).

Similarly, estimated value of $\mathrm{CO}$ for the cohort of maladapted PAH rats was significantly reduced for PAH rats $(72.6+/-5.1$; SE; $P<0.01$; Figure 5B).

\section{Histological Data}

\section{Fibrosis:}

During adaptive RV hypertrophy in PAH animals the percentage area to the RV free wall occupied by fibrotic tissue increased more than 2-fold (9.07 +/- $1.70 \%$; SE) compared to CTL (3.97 +/- $1.20 \%$; $P<$ 0.05; Figure 6A). However, with maladaptive RHF in PAH a further 1.8-fold increase (17.06 +/- $0.88 \% ; \mathrm{P}<$ 0.05 ) in fibrosis was observed in the RV free wall relative to the adapted RV cohort of PAH animals (Figure 6A).

\section{Vascularity:}


Changes in the RV free wall vascularity to PAH were assessed at both capillaries and arterioles levels. During adaptive RV hypertrophy the number of capillaries and arterioles in the RV free wall significantly decreased by $32 \%(P<0.05)$ and $21 \%(P<0.05)$, respectively, compared to CTL (Figure 6B). By contrast, in the maladaptive RHF/PAH cohort we observed a further significant decline in RV free wall capillaries and arterioles by $54 \%(P<0.01)$ and $65 \%(P<0.001)$, respectively, compared to the adaptive RV cohort (Figure 6B).

\section{IGF-1}

RV muscle IGF-1 protein expression was markedly decreased in the maladapted RHF/PAH rats compared to control animals $(P<0.005$; Figure 7A).

\section{Signaling Data}

For all protein studies in the RV muscle, phosphorylated proteins are expressed as the ratio of phosphorylated $(P)$ protein/total protein.

\section{PIBK/Akt:}

Phosphorylated Akt was markedly diminished by $63 \%$ in the maladapted/failed RV muscle compared to control rats (Figure 7B; $\mathrm{P}<0.005$ ).

\section{GSK-3 pathway:}

P-GSK-3 $\beta$ was assessed in the hearts of maladapted PAH and CTL rats. There was no significant difference in phosphorylation of GSK-3 $\beta$ between maladapted/failed RV of PAH and CTL hearts (Figure 8A).

\section{MAPKJERK pathway:}

Both P-p44 (ERK1) and P-p42 (ERK2) were assessed in the maladapted/failed RV of PAH and CTL rats. Values for both P-p44 and P-p42 were similar between maladapted PAH and CTL rats (Figure 8B \& C).

\section{mTOR:}

In the maladapted RV muscle, phosphorylated mTOR was significantly increased $(P<0.01$; Figure 9) suggesting activation by pathways separate from the PI3K/Akt signaling axis as P-Akt was markedly diminished (Figure 7B). To further explain this, we examined another possible signaling pathway that has recently been described to activate mTOR with subsequent autophagy inhibition [32].

\section{Autophagy pathway:}

The LC3BII/I ratio was analyzed as a surrogate marker of autophagosome formation. There was a significant decrease in the LC3BII/I ratio in maladapted/failed RV of PAH rats compared to CTL rats $(P<$ 0.05; Figure 9). Given the well-known role mTOR plays in regulating autophagy, we analyzed 
phosphorylated mTOR as stated above and its downstream effector $\mathrm{p} 70^{\mathrm{S} 6 \mathrm{~K}}$. P-mTOR and P-p $70^{\mathrm{S} 6 \mathrm{~K}}$ were significantly elevated in these PAH rats $(P<0.05$; Figure 9$)$. A recent publication identified a $p 27 / C D K 2$ axis in the regulation of mTOR-dependent inhibition of autophagy during heart failure [32]. p27 was significantly decreased in maladapted/failed RV of PAH rats relative to CTL $(P<0.05$; Figure 9). However, $\mathrm{p}$-CDK2 was not statistically different $(\mathrm{P}=0.22)$ in $\mathrm{PAH}$ rats which likely reflects variances and power influences (Figure 9).

\section{Discussion}

In this study, we evaluated over time, signaling events related to 3 key pathways known to be involved the early adaptive and physiologic response of the RV to the increased afterload presented to it in terms of in muscle protein synthesis and muscle hypertrophy in the adaptive phase of RV hypertrophy in the MCT model of PAH. We further examined in the phase of RV systolic decompensation /failure (often described as the maladaptive phase) what changes in these signaling pathways ensue and their consequences, particularly with prolonged mTOR activation [33]. What became evident is that even in the adaptive hypertrophy phase, there was the start of increased RV muscle fibrosis and a decline in RV muscle capillarity both of which markedly progressed further in the hemodynamically defined state of maladaptive hypertrophy. With regard to early increased

\section{Adaptive RV Hypertrophy.}

The time course studies revealed that a significant increase in RV systolic pressure predated the development of RV hypertrophy in PAH animals, like that described in previous studies [30,34]. This suggests that pressure overload was an important early stimulus to RV hypertrophy in an adaptive fashion. Several phosphorylated proteins in the RV of PAH rats were upregulated from all 3 of the major signaling pathways evaluated, peaking for the most part at day 24 in which established RV hypertrophy was evident. During this phase TAPSE and CO were preserved indicative of preserved RV systolic function.

\section{RV Fibrosis and Capillarity}

An interesting finding in our studies was that even in the hemodynamically defined state of adaptive RV hypertrophy in which TAPSE and CO were preserved and in which clinically, the rats exhibited no clinical features of RV failure (see below), there was evident a 2-fold increase in RV fibrosis compared with healthy controls and a 34\% decrease in capillarity as depicted in Figure 6. This in part may not be that unexpected, as there are robust data that RV diastolic dysfunction is evident in animal models of PAH and which precedes RV systolic dysfunction. RV diastolic dysfunction, with associated RV wall stiffness, impaired filling and prolonged relaxation is felt to be associated with RV myocardial fibrosis [35-37]. The reduced capillarity in the adaptive phase is intriguing and suggests multiple impacts on angiogenesis even at this early stage. While not examined in this study, the reduced levels of IGF- 1 in the RV myocardium may have in part contributed as IGF-1 is a potent angiogenesis factor [38]. Thus, a 
continuum of effects likely ensues in this progressive condition. Exactly what promotes the change is unknown. We speculate that when the burden of pathobiologic factors reaches a critical threshold, pathophysiologic features of RV systolic dysfunction and decompensation ensues.

\section{Signaling Pathways}

While there is an abundance of literature on the signaling pathways associated with cardiac hypertrophy, this reflects predominantly events in the LV. Data for the RV is limited, and especially so for serial measures over time.

PI3K/Akt/ mTOR pathway: In the present study, P-Akt, and P-mTOR were significantly upregulated at day 24 while downstream effectors, P-4E-BP1 and P-p70 $56 \mathrm{~K}$ were significantly upregulated at days 24 and 28, suggesting signaling events likely to impact on cardiac muscle protein synthesis. Akt activation phosphorylates a key regulatory domain of mTOR, which acts on downstream targets 4E-BP1 and p70 ${ }^{\mathrm{S} 6 \mathrm{~K}}$. Under conditions with low demand for mRNA translation and cardiac muscle protein synthesis, the translation repressor protein, 4E-BP1 sequesters eukaryotic initiation factor 4E (elF4E) preventing its interaction with other initiation factors (e.g., elF4G). Phosphorylation of 4E-BP1 leads to the dissociation of the $4 \mathrm{E}-\mathrm{BP} 1$.elF4e complex and the start of translation initiation [15]. This was indeed borne out in cardiac muscle (total heart homogenates) in which Vary and Lang [13] administered IGF-1 to rats showing increased phosphorylation of 4E-BP1 and reduced association with elF4E. IGF-1 administration also markedly increased P-Akt, P-mTOR and P-p70 $\left.{ }^{\text {S6K }}[13]\right)$. Of note, p70 ${ }^{\text {S6K }}$ phosphorylates a $40 \mathrm{~S}$ ribosomal protein S6, resulting in enhanced ribosomal binding capacity and protein translation for essential components of the muscle protein synthesis apparatus. The PI3K/Akt/mTOR pathway has also been shown to be upregulated in several models of hypertrophy of the LV, including in response to pressure overload [e.g., 10-12].

GSK-3 pathway: GSK-3 is known to play an important role in regulating glycogen metabolism in cardiac muscle. Further, its role in the integration of hypertrophic signaling in the heart has been increasingly emphasized [17]. While much importance has been placed on the $\beta$ isoform of GSK-3, there is increasing appreciation that the a isoform can also mediate cardiac hypertrophy [16]. Phosphorylation of GSK-3a $\left(\mathrm{Ser}^{21}\right)$ and $\beta\left(\mathrm{Ser}^{9}\right)$ inhibits their protein kinase activities, which diminishes GSK-3's inhibitory effects on eIF2 to promote protein translation and hypertrophy. While inhibition of GSK-3 in cardiac myocytes can be mediated by several other kinases (see below), its inhibition is likely largely mediated via PI3K/Akt signaling, with IGF-1 (and insulin) the most potent activators of Akt [39].

In the present study, there was increased phosphorylation of both GSK-3 $a$ and GSK-3 $\beta$ to similar extents, which coincided in time with the onset of RV hypertrophy at day 24. While P-GSK-3a remained at control levels at day 28 , surprisingly the levels of P-GSK-3 $\beta$ in the RV of PAH animals, was significantly reduced. It is unclear what signal/s mediated this effect.

MAPKJERK pathway: The MAPK comprises several family subtypes and is ubiquitously expressed amongst the body tissues, including in cardiac muscle [39]. The ERK1/2 subfamily is a prototypical 
pathway mainly responsive to growth factors (e.g., IGF-1 and insulin), while the p38 and JNK subfamilies are more "stress" responsive [40]. Activation of ERK1/2 by IGF-1 can occur via its tyrosine kinase receptor or independently, possibly via G proteins [41]. The Ras/Raf/Mek/ERK1/2 signaling pathways are regarded as having significant influences in promoting cardiomyocyte hypertrophy, in both in vitro as well as in vivo cardiac specific genetic models $[18,20]$. While ERK1/2 activation has been described with leftsided pressure overload [42], there is a paucity of data on ERK pathways in the context of right-sided pressure overload and RV hypertrophy. Increased levels of activated ERK were however reported in the RV in pulmonary artery banded fetal sheep [19]. It is thus of interest to report significantly increased expression of P-ERK1 and P-ERK2 at day 24 in PAH animals compared to controls, a time point at which significant RV hypertrophy emerged. In and of itself, it is unclear whether the ERK pathways are a dominant component of RV hypertrophy per se, or whether they only exert positive influences in conjunction with the effects of other signaling pathways [39].

\section{IGF-1}

The IGF-1 data we report in this time series study of adaptive RV hypertrophy are intriguing. While the marked increases in mRNA abundance in the RV at days 24 and 28 appeared to support IGF-1 as the key driver of the signaling events and RV muscle hypertrophy, this was not borne out by the protein assays for IGF-1. Indeed, no significant increment in IGF-1 expression was noted at any time point and at day 28 a significant $45 \%$ decrement was noted. How do we explain this discordance and the significant increments in activated signaling proteins observed? We speculate that there was a significant stimulus to produce IGF-1 induced by the increasing loads imposed on the RV over time, as noted by the 6.5 and 7.4 - fold increment in RV IGF-1 mRNA abundance at days 24 and 28. However, this stimulus did not result in concomitant increments in protein expression of IGF-1.

We speculate that several possible factors may have acted to impair translation of IGF-1 mRNA in our model. Firstly, inflammation has recently been highlighted in the pathobiology of PAH and most certainly plays a role in the MCT model [43 -45]. Indeed, inflammatory cytokines such as tumor necrosis factor (TNF)- $a$ can inhibit the action of IGF-1 in muscle [46]. Of interest, MCT -induced PAH in rats was attenuated by TNF- $\mathrm{a}$ antagonists via the suppression of TNF- $\alpha$ expression and the NF-KB pathway [47]. Further, MCT has been reported to activate NF-KB expression in the RV of the MCT-induced PAH model [48]. In addition, several inflammatory cytokines, including TNF-a, IL-1 $\beta$ and IL-6, are expressed in heart muscle and upregulated in heart failure and in the MCT model $[49,50]$. Thus IGF-1 expression may have been suppressed by the action of inflammatory cytokines. Significant body weight loss was observed in the PAH animals at days 24 and 28 compared with controls and malnutrition may also suppress IGF-1 expression in muscle tissue [25].

Secondly, it is possible that epigenetic factors such as influences of microRNAs may have repressed mRNA translation of IGF-1. MicroRNAs are small conserved non-coding RNA molecules that fine tune gene expression by either enhancing the degradation of mRNA or by inhibiting its translation [51]. Indeed, microRNA-1 (miR-1) was recently described to exhibit a feedback loop between it and the IGF-1 signaling 
cascade in cardiac muscle and that IGF-1 and its receptor are targets of miR-1 [52]. Further, there is an inverse relation between muscle IGF-1 and miR-1 [52], and several other miRs have been reported to influence IGF-1 in muscle [53]. We thus speculate that several possible influences in our model may have suppressed IGF-1 expression in the RV of PAH rats, despite a high stimulus to increase IGF-1 protein expression.

While we focused our studies on 3 major signaling pathways, we cannot rule out influences due to crosstalk with other pathways known to be implicated in cardiac muscle hypertrophy.

\section{Crosstalk between signaling pathways}

The pathways leading to RV hypertrophy in our model of PAH are clearly complex and likely involve signals from multiple key pathways as well as interaction with or crosstalk between the varieties of signals elaborated in this model. The calcium-dependent phosphatase, calcineurin, for example, has been implicated in pathological models of LV hypertrophy. Calcineurin dephosphorylates the transcription factor, NFAT-3 (nuclear factor of activated Tcells-3), which in combination with another transcription factor, GATA4, synergistically promotes cardiac gene transcription and hypertrophy [54, 55]. Of note, IGF-1 increases P-GATA4 and its nuclear accumulation in cardiac myocytes [56], while GSK-3 $\beta$ and ERK1/2 have also been shown to activate GATA4 in vitro $[57,58]$. However, GATA4 has robustly been shown not to be required for IGF-1 induced cardiac hypertrophy, which can proceed in its absence [56]. Further, activation of ERK1/2 by IGF-1 in cardiomyocytes may in part be mediated by protein kinase $\mathrm{C}$ alpha (PKCa) [59]. In our model, P-p70 ${ }^{\text {S6K }}$ was upregulated in the RV of PAH animals at days 24 and 28 likely mediated in large part by Akt/mTOR pathways. Interestingly, crosstalk between ERK and $\mathrm{p} 70^{\mathrm{S} 6 \mathrm{~K}}$ has been reported in cardiomyocytes [60].

Apart from PI3K/Akt mediated phosphorylation and inhibition of GSK-3a and $\beta$, other signaling pathways have been demonstrated to also phosphorylate and inactivate GSK-3 acting upon the same inhibitory sites as Akt [17]. These include Gq protein coupled receptor (GqPCR) agonists such as endothelin-1 (ET1), which is upregulated in PAH. ET-1 can stimulate PKC with subsequent activation of the ERK1/2 signaling cascade [16]. Further, ERK1/2 can phosphorylate and activate p90-ribosomal S6 kinase (RSK), which can then phosphorylate and inhibit GSK-3. Ligands for both $\alpha$ and $\beta$ adrenoreceptors can phosphorylate GSK-3 $\beta$, possibly via Akt activation [61]. Further, S6 kinases, Fas, and PKA can also inhibit GSK-3 [17].

Several pathways can signal through ERK to facilitate cardiomyocyte hypertrophy. In addition to growth factor signaling via tyrosine kinase receptors, signaling by adrenergic agonists, angiotensin and ET-1 via GqPCRs can also occur via MEK/ERK pathway signaling to mediate cardiac muscle protein synthesis and hypertrophy $[39,62]$.

\section{Maladapted RV Hypertrophy and Right Heart Failure}


Following the period of adaptive and physiologic RV hypertrophy the RV becomes progressively decompensated with eventual development of overt RHF. Further, echocardiography data support the notion that these animals had failing RVs as evinced by very low TAPSE and CO values together with a marked increase in RV muscle fibrosis and marked decrement in RV muscle capillarity, compared to CTL and MCT-treated animals in the adaptive phase. To gain insight into possible alterations in those signaling pathway patterns we described during the adaptive phase, we re-evaluated the GSK-3, MAPK/ERK, and mTOR pathways in the RV muscle of rats in whom clear RV dysfunction and failure had ensued.

\section{IGF-1}

Reduced expression of RV muscle IGF-1 has been well described in animal models of PH complicated by RV failure and was reduced by almost $50 \%$ in our RHF cohort compared to control values. Indeed, reduced IGF-1 has been described as part of the RV muscle failure molecular signature complicating PAH [63]. This suggests that many of the protean actions of IGF-1 on cardiac muscle would be severely impaired, such as its anabolic influences on RV muscle protein synthesis, as well as its anti-apoptotic, pro-angiogenic and positive inotropic actions, all of which could impair RV muscle function and contribute to the "sick" RV muscle milieu with RV decompensation and failure [64 -67].

\section{Signaling Pathways}

As highlighted above, much of the literature that relates to the signaling pathways we evaluated relates to the left ventricle. There are however limited data on the RV in the context of PAH which we refer to in support of our own data.

\section{Phosphorylated Akt:}

Data in our PH model complicated by a decompensated/failed RV show marked reduction in phosphorylated Akt. Similar findings have been reported in several animal models of the pressure overloaded LV accompanied by LV hypertrophy and heart failure due to transverse aortic constriction [68, 69] or with doxorubicin-induced cardiomyopathy [70]. The PI3K/Akt pathway has been highlighted as important in physiologic adaptive cardiac hypertrophy and to exert a protective role particularly under conditions of stress. Thus, the markedly diminished expression of p-Akt in the decompensated RV muscle would be expected to negatively impact on several signaling pathways known to promote a healthy RV milieu. Our findings are in contrast to those reported for the Sugen/Hypoxia model of PAH and RV decompensation in which mTORC2-Akt levels were unaffected, while mTORC1 signaling in the RV muscle was upregulated [14].

\section{GSK3 pathway:}

We were surprised that the expression of GSK-3 $\beta$ in the decompensated RV muscle was preserved. In states of nutritional stress, we reported that GSK-3 and ERK expression was suppressed along with reduced p-Akt [15]. However, it is of interest that GSK-3 $\beta$ was previously reported as increased in the RV of 
MCT treated rats [71] as well as in the LV of LV pressure overload and heart failure [69] with a late reduction reported. We speculate that the preservation of GSK-3 expression may reflect an attempt to preserve muscle protein synthesis in an otherwise stress-induced catabolic and apoptotic environment.

\section{MAPKJERK pathway:}

In the present study, the RV expression of p42 and p44 in the maladapted state was preserved in our cohort. Similar to the data for GSK-3 $\beta$, ERK1/2, levels in the pressure overloaded maladapted LV were initially increased [69]. The implications are likely similar as speculated for GSK-3 $\beta$ and there are data suggesting an anti-apoptotic function of cardiac ERK signaling [72].

\section{mTOR:}

Another unexpected finding was a significant and marked increase in p-mTOR expression in the maladapted RV muscle, given the markedly reduced p-Akt. Thus, it appears that mTOR is not activated via the PI3K/Akt pathway in maladaptive RV hypertrophy, unlike signaling in adaptive RV hypertrophy. Similarly, Deng and coworkers [73] reported increased p-mTOR in the decompensated/failed RV muscle 42 days post MCT administration in rats. Further, Pena and coworkers reported upregulation of mTORC1 in the maladapted RV of rats with severe PAH induced by Sugen/Hypoxia [14]. We thus evaluated other possible sources of mTOR activation independent of Akt and ERK signaling, as described below.

\section{Dysregulated Autophagy and Implications for Right Heart Failure}

Recently a p27/cyclin dependent kinase inhibitor (CDK2)/mTOR signaling pathway has been described in cardiac muscle regulated by miR-221 [32]. Activation of this pathway has been shown to increase the expression and activity of mTOR. In cardiomyocytes, p27 has been shown to be anti-hypertrophic and is down regulated in heart failure in response to pressure overload [74, 75]. Moreover, mice deficient of p27 develop cardiac hypertrophy and heart failure [76]. What has also been observed in transgenic mice in which miR-221 (or miR-222) are overexpressed, is that there is the induction of heart failure with associated mTOR activation and autophagy inhibition [32, 77].

Autophagy is a conserved intracellular process geared to remove misfolded proteins and damaged intracellular organelles which are digested in autophagolysosomes [78]. Autophagy inhibition mediated by activated mTOR, transcription factor EB, miR-365 and Eva-1 homologue A knockout, are all associated with the development of heart failure [79 - 82]. Autophagy inhibition may also promote apoptosis of cardiomyocytes [77].

In the present study, we demonstrated that p27 is significantly downregulated in the maladapted RV muscle and that mTOR is increased with evidence to suggest autophagy inhibition as evinced by significant decrease in the LC3BII/I ratio, suggesting this signaling axis is active in our model. Further it has been proposed that pronged mTORC1 activation in the RV muscle in the Sugen/Hypoxia model of PAH results in decreased autophagy [33]. 


\section{Conclusions}

We began this investigation examining those signaling pathways thought to be key in cardiac muscle protein synthesis (PI3K/Akt/mTOR; GSK-3; ERK) in a temporal fashion during the development of adaptive hypertrophy in the MCT model of PAH. While the direction of change seen in the 3 major signaling pathways appear to support enhanced cardiac muscle protein synthesis during this evolving physiologic adaptation, the discordance between high IGF-1 mRNA and protein suggests that in the MCT model IGF-1 is not a major driver or that its attempts to drive anabolism are inhibited by multiple factors, as alluded to above. Examination of the 3 pathways in the maladapted/failed RV yield unexpected data and new data for RHF that autophagy inhibition may contribute to adverse RV pathobiology and poor RV function. Lastly we speculate taking all data into account that a continuum of changes characterizes the adaptive and maladaptive phases in the RV muscle and that a threshold effect in certain parameters likely determines whether overt pathophysiological changes (such as RV systolic dysfunction/failure) ensue as the disease progresses.

\section{Abbreviations}

PAH: Pulmonary Arterial Hypertension, RV: Right Ventricle, LV: Left Ventricle, S: Septum, RHF: Right Heart Failure, MCT: Monocrotaline, CTL: Control, TAPSE: Tricuspid Annular Systolic Plane Excursion, PA VTI: Pulmonary Artery Velocity Time Integral, SV: Stroke Volume, CO: Cardiac Output

\section{Declarations}

Author Contributions: Conception/design of study MF and MIL; data collection and analysis MF, RGR, RCM BSG and XX; data interpretation MF, RGR, RCM and MIL; statistical analysis and figures MF, RCM, RGR and MIL; drafting of manuscript MF, RCM, BSG and MIL; editing and revising of manuscript MF, RCM and MIL; final version approval MF and MIL

\section{Acknowledgements}

The authors gratefully acknowledge Guangzhu Zhang for her skilled technical assistance and Eduardo Marbán, M.D., Ph.D., for his insightful review and advice on this project.

\section{Availability of the data}

The datasets used and/or analyzed during the current study will be made available from the corresponding author on reasonable request.

\section{Animal welfare ethics approval}

This research conformed to the Guide for the Care and Use of Laboratory Animals (NIH Publication No. 85-23, revised 1996). The research protocol was approved by the Institutional Animal Care and Use Committee of the Burns and Allen Research Institute at Cedars Sinai Medical Center. 


\section{Consent for publication}

Not Applicable

\section{Funding Sources}

This work was supported by research grants from the Brandman Foundation, the Plum Foundation and the California Institute of Regenerative Medicine (CLIN2-09444). These sponsors provided only financial support for the conduct of the research and had no involvement in any scientific aspect of the study.

\section{Competing interests}

The authors declare that they have no competing interests.

\section{References}

1. Humbert M, Sitbon O, Chaouat A, Bertocchi M, Habib G, Gressin V, Yaïci A, Weitzenblum E, Cordier JF, Chabot F, Dromer C, Pison C, Reynaud-Gaubert M, Haloun A, Laurent M, Hachulla E, Cottin V, Degano B, Jaiis X, Montani D, Souza R, Simonneau G. Survival in patients with idiopathi-1c, familial, and anorexigenassociated pulmonary arterial hypertension in the modern management era. Circulation 2010; 122:156163.

2. Farber HW, Miller DP, Poms AD, Badesch DB, Frost AE, Muros-Le Rouzic E, Romero AJ, Benton WW, Elliott CG, McGoon MD, Benza RL. Five-Year outcomes of patients enrolled in the REVEAL Registry. Chest 2015; 148:1043-1054.

3. Barst RJ, Chung L, Zamanian RT, Turner M, McGoon MD. Functional class improvement and 3year survival outcomes in patients with pulmonary arterial hypertension in the REVEAL Registry. Chest 2013; 144:16016-16018.

4. Vonk-Noordegraaf A, Haddad F, Chin KM, Forfia PR, Kawut SM, Lumens J, Naeije R, Newman J, Oudiz RJ, Provencher S, Torbicki A, Voelkel NF, Hassoun PM. Right heart adaptation to pulmonary arterial hypertension: physiology and pathobiology. J Am Coll Cardio 2013; 62 (25 Suppl):D22-33.

5. Benza RL, Miller DP, Gomberg-Maitland M, Frantz RP, Foreman AJ, Coffey CS, Frost A, Barst RJ, Badesch DB, Elliott CG, Liou TG, McGoon MD. Predicting survival in pulmonary arterial hypertension: insights from the Registry to Evaluate Early and Long-Term Pulmonary Arterial Hypertension Disease Management (REVEAL). Circulation 2010; 122:164-172.

6. Forfia PR, Fisher MR, Mathai SC, Housten-Harris T, Hemnes AR, Borlaug BA, Chamera E, Corretti MC, Champion HC, Abraham TP, Girgis RE, Hassoun PM. Tricuspid annular displacement predicts survival in pulmonary hypertension. Am J Respir Crit Care Med 2006; 174:1034-1041. 
7. Mauritz GJ, Kind T, Marcus JT, Bogaard HJ, van de Veerdonk M, Postmus PE, Boonstra A, Westerhof N, Vonk-Noordegraaf A. Progressive changes in right ventricular geometric shortening and long-term survival in pulmonary arterial hypertension. Chest 2012;141: 935-943.

8. D'Alonzo GE, Barst RJ, Ayres SM, Bergofsky EH, Brundage BH, Detre KM, Fishman AP, Goldring RM,Groves BM, Kernis JT, Levy PS, Pietra GG, Reid LM, Reeves JT, Rich S, Vreim CE, Williams GW, Wu M. Survival in patients with primary pulmonary hypertension: Results from a National Prospective Registry. Ann Intern Med 1991; 115: 343-349.

9. Bodine SC, Stitt TN, Gonzalez M, Kline WO, Stover GL, Bauerlein R, Zlotchenko E, Scrimgeour A, Lawrence JC, Glass DJ, Yancopoulos GD. Akt/mTOR pathway is a crucial regulator of skeletal muscle hypertrophy and can prevent muscle atrophy in vivo. Nat Cell Biol 2001; 3:1014-1019.

10. Hua Y, Zhang Y, Ren J. IGF-1 deficiency resists cardiac hypertrophy and myocardial contractile dysfunction: role of microRNA-1 and microRNA-133a. J Cell Mol Med 12012; 6: 83-95.

11. Kim J, Wende AR, Sena S, Theobald HA, Soto J, Sloan C, Wayment BE, Litwin SE, Holzenberger $M$, LeRoith D, Abel ED. Insulin-like growth factor I receptor signaling is required for exercise-induced cardiac hypertrophy. Mol Endocrinol 2008; 22:2531-2543.

12. McMullen JR, Shioi T, Huang WY, Zhang L, Tarnavski O, Bisping E, Schinke M, Kong S, Sherwood MC, Brown J, Riggi L, Kang PM, Izumo S. The insulin-like growth factor 1 receptor induces physiological heart growth via the phosphoinositide 3-kinase (p110alpha) pathway. J Biol Chem 2004; 279:4782-4793.

13. Vary TC, Lang CH. IGF-I activates the elF4F system in cardiac muscle in vivo. Mol Cell Biochem $2005 ; 272: 209-220$.

14. Pena A, Kobir A, Goncharov D, Goda A, Kudryashova TV, Ray A, Vanderpool R, Baust J, Chang B, Mora AL, Gorcsan J 3rd, Goncharova EA. Pharmacological Inhibition of mTOR Kinase Reverses Right Ventricle Remodeling and Improves Right Ventricle Structure and Function in Rats. Am J Respir Cell Mol Biol 2017; 57:615-625.

15. Lewis MI, Bodine SC, Kamangar N, Xu X, Da X, Fournier M. Effect of severe short-term malnutrition on diaphragm muscle signal transduction pathways influencing protein turnover. J Appl Physiol 2006;100:1799-1806.

16. Markou T, Cullingford TE, Giraldo A, Weiss SC, Alsafi A, Fuller SJ, Clerk A, Sugden PH. Glycogen synthase kinases 3 alpha and 3beta in cardiac myocytes: regulation and consequences of their inhibition. Cell Signal 2008; 20:206-218.

17. Sugden PH, Fuller SJ, Weiss SC, Clerk A. Glycogen synthase kinase 3 (GSK3) in the heart: a point of integration in hypertrophic signalling and a therapeutic target? A critical analysis. Br J Pharmacol 2008; 153:S137-S153. 
18. Bueno OF, De Windt LJ, Tymitz KM, Witt SA, Kimball TR, Klevitsky R, Hewett TE, Jones SP, Lefer DJ, Peng CF, Kitsis RN, Molkentin JD. The MEK1-ERK1/2 signaling pathway promotes compensated cardiac hypertrophy in transgenic mice. EMBO J 2000; 19:6341-6350.

19. Olson AK, Protheroe KN, Scholz TD, Segar JL. Activation of the mitogen-activated protein kinases and Akt in response to pulmonary artery banding in the fetal sheep heart is developmentally regulated. Neonatology 2008; 93:145-152.

20. Ueyama T, Kawashima S, Sakoda T, Rikitake Y, Ishida T, Kawai M, Yamashita T, Ishido S, Hotta H, Yokoyama M. Requirement of activation of the extracellular signal-regulated kinase cascade in myocardial cell hypertrophy. J Mol Cell Cardiol 2000; 32:947-960.

21. Lewis MI, Horvitz, GD, Clemmons DR, Fournier M. Role of IGF-1 and IGF binding proteins within diaphragm muscle in modulating the effects of nandrolone. Am J Physiol Endocrinol Metab 2002; 282:E483-E490.

22. Ebensperger R, Acevedo E, Meléndez J, Corbalán R, Acevedo M, Sapag-Hagar M, Jalil JE, Lavandero S. Selective increase in cardiac IGF-1 in a rat model of ventricular hypertrophy. Biochem Biophys Res Commun 1998; 243:20-24.

23. Honsho S, Nishikawa S, Amano K, Zen K, Adachi Y, Kishita E, Matsui A, Katsume A, 22. Yamaguchi S, Nishikawa K, Isoda K, Riches DW, Matoba S, Okigaki M, Matsubara H. Pressure-mediated hypertrophy and mechanical stretch induces IL-1 release and subsequent IGF-1 generation to maintain compensative hypertrophy by affecting Akt and JNK pathways. Circ Res 2009; 105:1149-1158.

24. McMullen JR, Shioi T, Zhang L, Tarnavski O, Sherwood MC, Kang PM, Izumo S. Phosphoinositide 3-kinase (p110alpha) plays a critical role for the induction of physiological, but not pathological, cardiac hypertrophy. Proc Natl Acad Sci USA 2003; 100:12355-12360.

25. Lewis MI, Li H, Huang ZS, Biring MS, Cercek B, Fournier M. Influence of varying degrees of malnutrition on IGF-I expression in the rat diaphragm. J Appl Physiol 2003; 95:555-562.

26. IHC World. http://www.ihcworld.com/_protocols/special_stains/sirius_red.htm

27. Whittaker P, Kloner RA, Boughner DR, Pickering JG. Quantitative assessment of myocardial collagen with picrosirius red staining and circularly polarized light. Basic Res Cardiol 1994; 89:397-410.

28. Awal M. Hadi, Koen T. B. Mouchaers, Ingrid Schalij, Katrien Grunberg, Gerrit A. Meijer, Anton Vonk-Noordegraaf, Willem J. van der Laarse, Jeroen A. M. Beliën, "Rapid Quantification of Myocardial Fibrosis: A New Macro-Based Automated Analysis", Analytical Cellular Pathology, vol. 33, Article ID 858356, 13 pages, 2010.

29. https://imagej.nih.gov/ij/docs/examples/stained-sections/index.html 
30. Middleton RC, Fournier M, Xu X, Marbán E, Lewis MI. Therapeutic benefits of intravenous cardiosphere-derived cell therapy in rats with pulmonary hypertension. PLoS One. 2017 Aug 24;12(8):e0183557. doi: 10.1371/journal.pone.0183557. PMID: 28837618; PMCID: PMC5570343..

31. Vogel J. Measurement of cardiac output in small laboratory animals using recordings of blood conductivity. Am J Physiol Heart Circ Physiol 1997; 273:H2520-H2527.

32. Su M, Wang J, Wang C, Wang X, Dong W, Qiu W, Wang Y, Zhao X, Zou Y, Song L, Zhang L, Hui R. MicroRNA-221 inhibits autophagy and promotes heart failure by modulating the $\mathrm{p} 27 / \mathrm{CDK} 2 / \mathrm{mTOR}$ axis. Cell Death Differ 2015; 22:986-999.

33. Houssaini A, Adnot S. mTOR: A Key to Both Pulmonary Vessel Remodeling and Right Ventricular Function in Pulmonary Arterial Hypertension? Am J Respir Cell Mol Biol 2017; 57:509-511.

34. Henkens IR, Mouchaers KT, Vliegen HW, van der Laarse WJ, Swenne CA, Maan AC, Draisma HH, Schalij I, van der Wall EE, Schalij MJ, Vonk-Noordegraaf A. Early changes in rat hearts with developing pulmonary arterial hypertension can be detected with three-dimensional electrocardiography. Am J Physiol Heart Circ Physiol 2007; 293:H1300-H1307.

35. Rain S, Handoko ML, Trip P, Gan CT, Westerhof N, Stienen GJ et al. 2013. Right ventricular diastolic impairment in patients with pulmonary arterial hypertension. Circulation 2013; 128:2016-2025.

36. Trip P, Rain, S, Handoko ML, van der Bruggen C, Bogaard HJ, Marcus JT , Boonstra A, Nico Westerhof N, Anton Vonk-Noordegraaf A, de Man FS. Clinical relevance of right ventricular diastolic stiffness in pulmonary hypertension. Eur Respir J 2015; 45:1603-1612.

37. Murch SD, La Gerche A, Roberts TJ, Prior DL, Maclsaac Al, Burns AT. Abnormal right ventricular relaxation in pulmonary hypertension. Pulm Circ 2015; 5:370-375.

38. Bach , LA. Endothelial cells and the IGF system. J Mol Endocrinol 2015; 54:R1-R13.

39. Rose BA, Force T, Wang Y. Mitogen-activated protein kinase signaling in the heart: angels versus demons in a heart-breaking tale. Physiol Rev 2010; 90:1507-1546.

40. Ramos JW. The regulation of extracellular signal-regulated kinase (ERK) in mammalian cells. Int J Biochem Cell Biol 2008; 40:2707-2719.

41. Perrault R, Wright B, Storie B, Hatherell A, Zahradka P. Tyrosine kinase-independent activation of extracellular-regulated kinase (ERK) $1 / 2$ by the insulin-like growth factor-1 receptor. Cell Signal 2011; 23:739-746.

42. Takeishi Y, Huang Q, Abe J, Glassman M, Che W, Lee JD, Kawakatsu H, Lawrence EG, Hoit BD, Berk BC, Walsh RA. Src and multiple MAP kinase activation in cardiac hypertrophy and congestive heart 
failure under chronic pressure-overload: comparison with acute mechanical stretch. J Mol Cell Cardiol. 2001; 33:1637-1648.

43. Wilson DW, Segall HJ, Pan LC, Dunston SK. Progressive inflammatory and structural changes in the pulmonary vasculature of monocrotaline-treated rats. Microvasc Res 1989; 38:57-80.

44. Rabinovitch M, Guignabert C, Humbert M, Nicolls MR. Inflammation and immunity in the pathogenesis of pulmonary arterial hypertension. Circ Re. 2014; 115:165-175.

45. Le Hiress M, Tu L, Ricard N, Phan C, Thuillet R, Fadel E, Dorfmüller P, Montani D, de Man F, Humbert M, Huertas A, Guignabert C. Pro-inflammatory Signature of the Dysfunctional Endothelium in Pulmonary Hypertension. Role of the Macrophage Migration Inhibitory Factor/CD74 Complex. Am J Respir Crit Care Med 2015; 192:983-997.

46. Fernandez-Celemin L, Pasko N, Biomart V, Thissen JP. Inhibition of muscle IGF-1 expression by tumor necrosis factor - alpha. Am J Physiol Endocrinol Metab 2002; 283:E279-E290.

47. Wang Q, Zuo XR, Wang YY, Xie WP, Wang H, Zhang M. Monocrotaline-induced pulmonary arterial hypertension is attenuated by TNF- $a$ antagonists via the suppression of TNF- $a$ expression and NF-KB pathway in rats. Vascul Pharmacol 2013; 58:71-77.

48. Kumar S, Wei C, Thomas CM, Kim IK, Seqqat R, Kumar R, Baker KM, Jones WK, Gupta S. Cardiacspecific genetic inhibition of nuclear factor-KB prevents right ventricular hypertrophy induced by monocrotaline. Am J Physiol Heart Circ Physiol 2012; 302:H1655-1666.

49. Price LC, Montani D, Tcherakian C, Dorfmüller P, Souza R, Gambaryan N, Chaumais MC, Shao DM, Simonneau G, Howard LS, Adcock IM, Wort SJ, Humbert M, Perros F. Dexamethasone reverses monocrotaline-induced pulmonary arterial hypertension in rats. Eur Respir J. 2011; 37:813-822.

50. Kubota T, Miyagishima M, Alvarez R, Kormos R, Demetris A, Semigran M, Dec G, Holubkov R, McTiernan C, Mann D, Feldman A, McNamara D. Expression of proinflammatory cytokines in the failing heart: comparison of recent onset and end-stage congestive heart failure. J Heart Lung Transplant 2000; 19:819-824.

51. Bartel DP. MicroRNAs: target recognition and regulatory functions. Cell 2009;136:215-233.

52. Elia L, Contu R, Quintavalle M, Varrone F, Chimenti C, Russo M, Cimino V, De Marinis L, Frustaci A, Catalucci D, Condorelli G. Reciprocal regulation of microRNA-1 and insulin like growth factor -1 signal transduction cascade in cardiac and skeletal muscle in physiologic and pathological conditions. Circulation 2009; 120:2377-2385.

53. Hitachi K, Tsuchida K. Role of microRNAs in skeletal muscle hypertrophy. Frontiers in Physiology $2014 ; 4: 408$. 
54. Molkentin JD, Lu JR, Antos CL, Markham B, Richardson J, Robbins J, Grant SR, Olson EN. A calcineurin-dependent transcriptional pathway for cardiac hypertrophy. Cell 1998; 93:215-228.

55. Wilkins BJ, Dai YS, Bueno OF, Parsons SA, Xu J, Plank DM, Jones F, Kimball TR, Molkentin JD. Calcineurin/NFAT coupling participates in pathological, but not physiological, cardiac hypertrophy. Circ Res 2004; 94:110-118.

56. Bisping E, Ikeda S, Sedej M, Wakula P, McMullen JR, Tarnavski O, Sedej S, Izumo S, Pu WT, Pieske B. Transcription factor GATA4 is activated but not required for insulin-like growth factor 1 (IGF1)-induced cardiac hypertrophy. J Biol Chem 2012; 287:9827-9834.

57. Liang Q, Wiese RJ, Bueno OF, Dai YS, Markham BE, Molkentin JD. The transcription factor GATA4 is activated by extracellular signal-regulated kinase 1-and 2-mediated phosphorylation of serine 105 in cardiomyocytes. Mol Cell Biol; 2001; 21:7460-7469.

58. Morisco C, Seta K, Hardt SE, Lee Y, Vatner SF, Sadoshima J. Glycogen synthase kinase 3beta regulates GATA4 in cardiac myocytes. J Biol Chem 2001; 276:28586-28597.

59. Pecherskaya A, Solem M. IGF1 activates PKC alpha-dependent protein synthesis in adult rat cardiomyocytes. Mol Cell Biol Res Commun 2000; 4:166-171.

60. Wang L, Gout I, Proud CG. Cross-talk between the ERK and p70 S6 kinase (S6K) signaling pathways. MEK-dependent activation of S6K2 in cardiomyocytes. J Biol Chem 2001; 276:32670-32677.

61. Morisco C, Zebrowski D, Condorelli G, Tsichlis P, Vatner SF, Sadoshima J. TheAkt-glycogen synthase kinase 3 beta pathway regulates transcription of atrial natriuretic factor induced by betaadrenergic receptor stimulation in cardiac myocytes. J Biol Chem 2000; 275:14466-14475.

62. Proud CG. Ras, PI3-kinase and mTOR signaling in cardiac hypertrophy. Cardiovasc Res 2004; 63:403-413.

63. Drake JI, Bogaard HJ, Mizuno S, Clifton B, Xie B, Gao Y, Dumur Cl, Fawcett P, Voelkel NF, Natarajan R. Molecular signature of a right heart failure program in chronic severe pulmonary hypertension. Am J Respir Cell Mol Biol 2011; 45:1239-1247.

64. van de Veerdonk MC, Bogaard HJ, Voelkel NF. The right ventricle and pulmonary hypertension. Heart Fail Rev 2016; 21:259-271.

65. Reddy S, Bernstein D. Molecular Mechanisms of Right Ventricular Failure. Circulation 2015; 132:1734-1742.

66. Ryan JJ, Huston J, Kutty S, Hatton ND, Bowman L, Tian L, Herr JE, Johri AM, Archer SL. Right ventricular adaptation and failure in pulmonary arterial hypertension. Can J Cardiol 2015; 31:391-406. 
67. Bogaard HJ, Abe K, Vonk Noordegraaf A, Voelkel NF. The right ventricle under pressure: cellular and molecular mechanisms of right-heart failure in pulmonary hypertension. Chest 2009; 135:794-804.

68. Kemi OJ, Ceci M, Wisloff U, Grimaldi S, Gallo P, Smith GL, Condorelli G, Ellingsen O. Activation or inactivation of cardiac Akt/mTOR signaling diverges physiological from pathological hypertrophy. J Cell Physiol 2008; 214:316-321.

69. Li XM, Ma YT, Yang YN, Liu F, Chen BD, Han W, Zhang JF, Gao XM. Downregulation of survival signalling pathways and increased apoptosis in the transition of pressure overload-induced cardiac hypertrophy to heart failure. Clin Exp Pharmacol Physiol 2009; 36:1054-1061.

70. Chen YL, Chung SY, Chai HT, Chen CH, Liu CF, Chen YL, Huang TH, Zhen YY, Sung PH, Sun CK, Chua S, Lu HI, Lee FY, Sheu JJ, Yip HK. Early administration of Carvedilol protected against Doxorubicininduced cardiomyopathy. J Pharmacol Exp Ther 2017; 355:516-527.

71. Colombo R, Siqueira R, Becker CU, Fernandes TG, Pires KM, Valença SS, Souza-Rabbo MP, Araujo AS, Belló-Klein A. Effects of exercise on monocrotaline-induced changes in right heart function and pulmonary artery remodeling in rats. Can J Physiol Pharmacol 2013; 91:38-44.

72. Purcell NH, Wilkins BJ, York A, Saba-El-Leil MK, Meloche S, Robbins J, Molkentin JD. Genetic inhibition of cardiac ERK1/2 promotes stress-induced apoptosis and heart failure but has no effect on hypertrophy in vivo. Proc Natl Acad Sci USA 2007; 104:14074-14079.

73. Deng Y, Wu W, Guo S, Chen Y, Liu C, Gao X, Wei B. Altered mTOR and Beclin-1 mediated autophagic activation during right ventricular remodeling in monocrotaline-induced pulmonary hypertension. Respir Res 2017; 18:53 (1-15).

74. Li JM, Brooks G. Downregulation of cyclin-dependent kinase inhibitors p21 and p27 in pressureoverload hypertrophy. Am J Physiol 1997;273: H1358-H1367.

75. Burton PB, Yacoub MH, Barton PJ. Cyclin-dependent kinase inhibitor expression in human heart failure. A comparison with fetal development. Eur Heart J 1999; 20:604-611.

76. Hauck L, Harms C, An J, Rohne J, Gertz K, Dietz R, Endres M, von Harsdorf R. Protein kinase CK2 links extracellular growth factor signaling with the control of p27(Kip1) stability in the heart. Nat Med 2008; 14:315-324.

77. Su M, Chen Z, Wang C, Song L, Zou Y, Zhang L, Hui R, Wang J. Cardiac-Specific Overexpression of miR-222 Induces Heart Failure and Inhibits Autophagy in Mice. Cell Physiol Biochem 2016; 39:15031511.

78. Linton PJ, Gurney M, Sengstock D, Mentzer RM Jr, Gottlieb RA. This old heart: Cardiac aging and autophagy. J Mol Cell Cardio. 2015; 83:44-54. 
79. Bartlett JJ, Trivedi PC, Yeung P, Kienesberger PC, Pulinilkunnil T. Doxorubicin impairs cardiomyocyte viability by suppressing transcription factor EB expression and disrupting autophagy. Biochem J 2016; 473:3769-3789.

80. Wu H, Wang Y, Wang X, Li R, Yin D. MicroRNA-365 accelerates cardiac hypertrophy by inhibiting autophagy via the modulation of Skp2 expression. Biochem Biophys Res Commun. 2017; 484: 304-310.

81. Zhang S, Lin X, Li G, Shen X, Niu D, Lu G, Fu X, Chen Y, Cui M, Bai Y. Knockout of Eva1a leads to rapid development of heart failure by impairing autophagy. Cell Death Dis 2017; 8(2):e2586.

82. Sciarretta S, Forte M, Frati G, Sadoshima J. New insights into the role of mTOR signaling in the cardiovascular system. Circ Res 2018; 122:489-505.

\section{Figures}

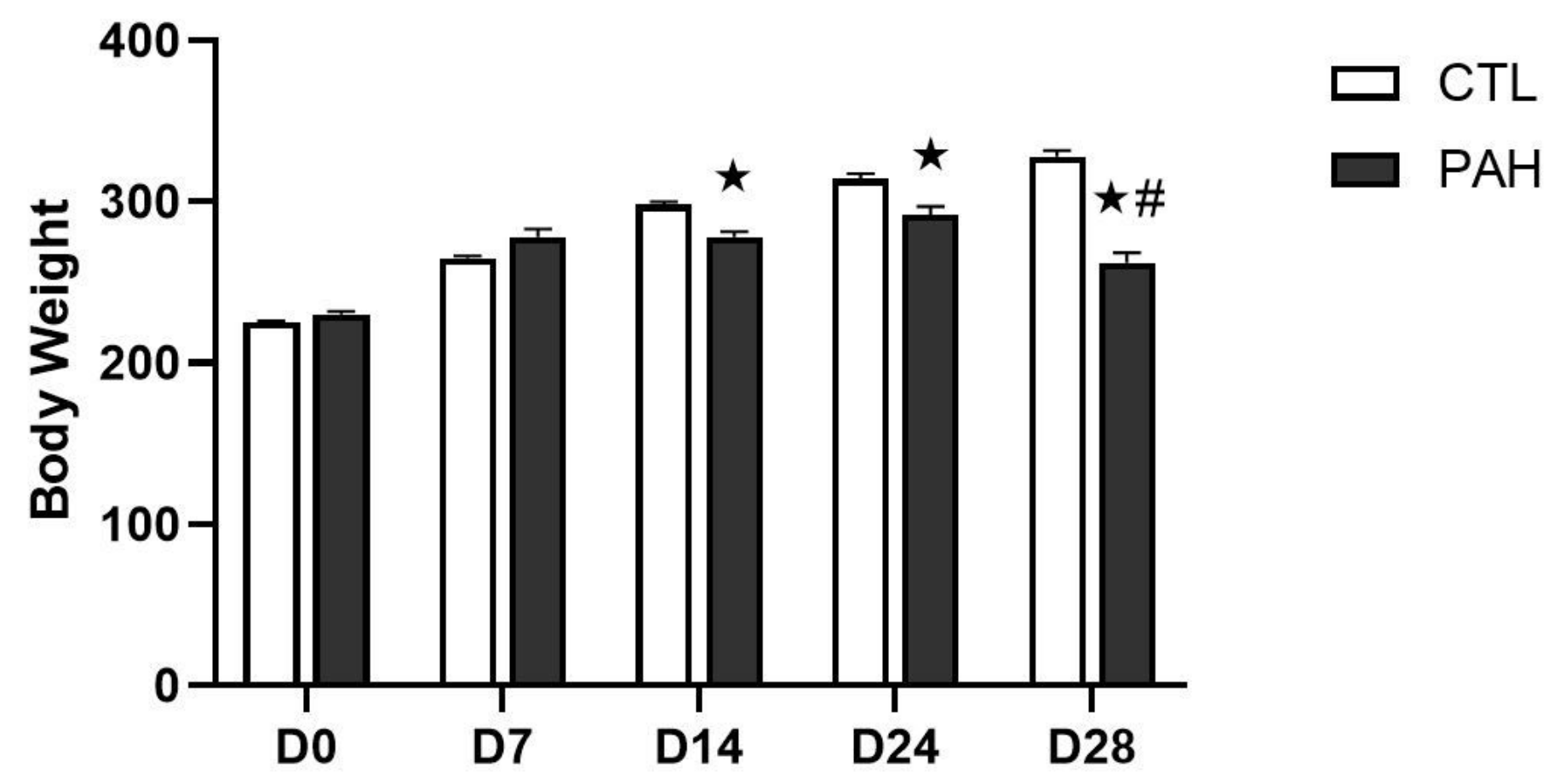

Figure 1

Body weights of healthy and PAH animals. Body weights of control (CTL) and pulmonary arterial hypertension (PAH) animals at days $0,7,14,24$, and 28 . Values are means $\pm S E M$; $\Downarrow$ significantly different from CTL; \# significantly different from day $24 \mathrm{PAH}$. 
A.

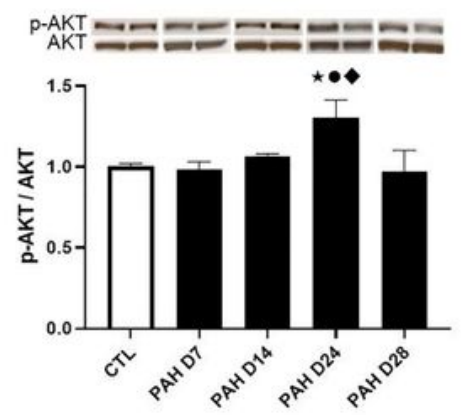

B.

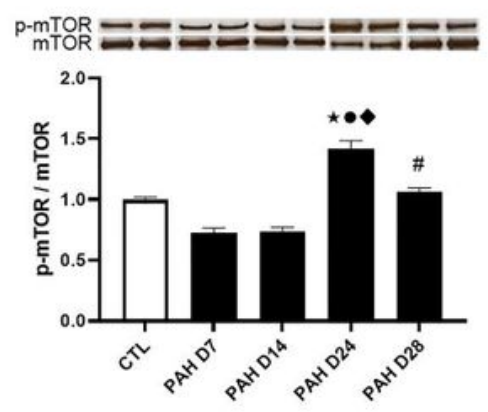

c.

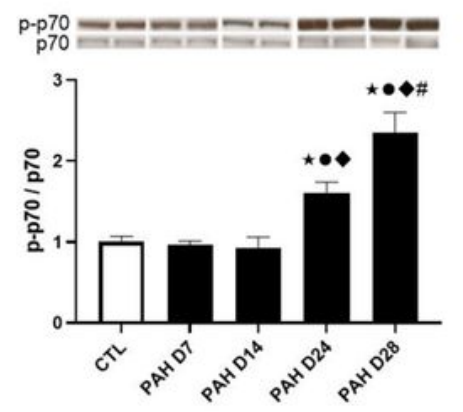

D.

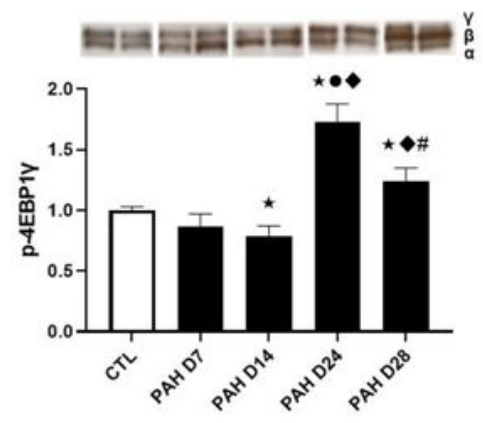

Figure 2

AKT/mTOR signaling in the right ventricle of healthy and PAH animals (A) Ratio of phosphorylated p-Akt (Ser473) to total Akt and (B) p-mTOR (Ser2448) to total mTOR in the right ventricle of control (CTL) and pulmonary arterial hypertension (PAH) animals at days $0,7,14,24$, and 28. (C) Ratio of phosphorylated pp70S6K (Thr389) to total p70S6K and (D) hyperphosphorylated 4E-BP1 (PHAS-I) in the right ventricle of control (CTL) and pulmonary arterial hypertension (PAH) animals at days $0,7,14,24$, and 28 . Values are 


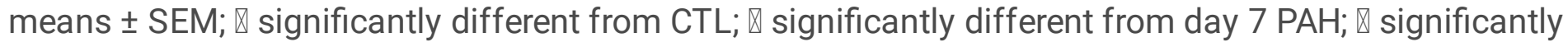
different from day $14 \mathrm{PAH}$; \# significantly different from day $24 \mathrm{PAH}$.

A.

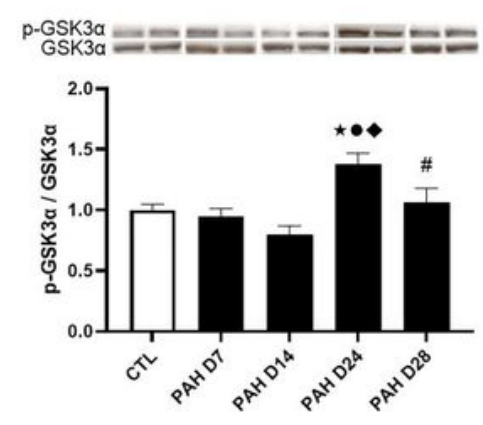

B.

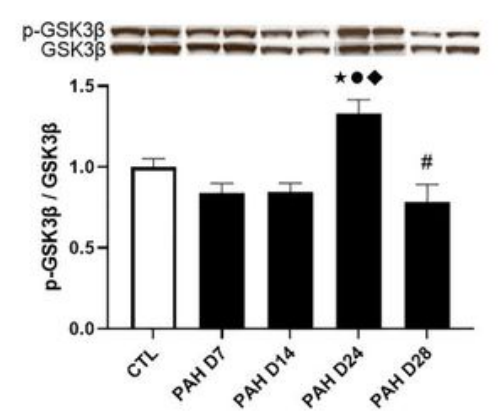

c.

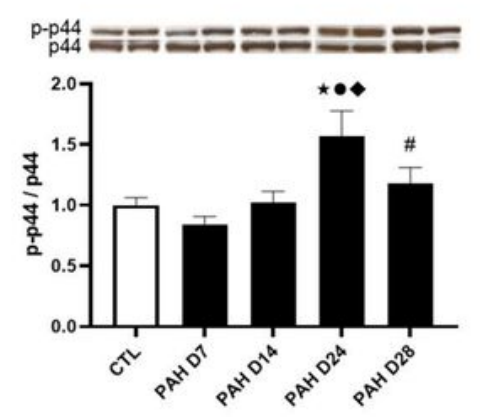

D.

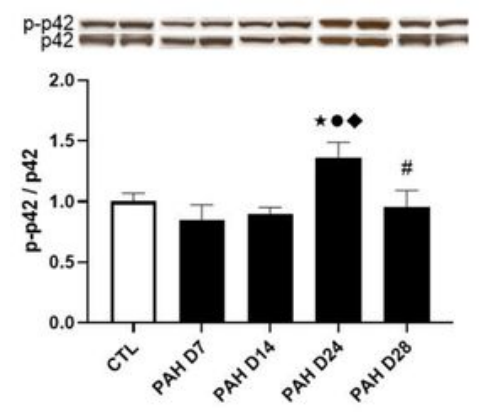

Figure 3

Ratio of "The p42/p44 MAP Kinase Pathway" (A) Ratio of phosphorylated p-GSK-3a (Ser21) to total GSK$3 \alpha$ and (B) p-GSK-3 $\beta$ (Ser9) to total GSK-3 $\beta$ in the right ventricle of control (CTL) and pulmonary arterial hypertension (PAH) animals at days $0,7,14,24$, and 28. (C) Ratio of phosphorylated p-p44 (Thr202) to 
total p44 and (D) p-p42 (Tyr204) to total p42 in the right ventricle of control (CTL) and pulmonary arterial hypertension (PAH) animals at days $0,7,14,24$, and 28 . Values are means $\pm S E M ; \otimes$ significantly different from CTL; $\otimes$ significantly different from day $7 \mathrm{PAH} ; \otimes$ significantly different from day $14 \mathrm{PAH}$; \# significantly different from day $24 \mathrm{PAH}$.

A.

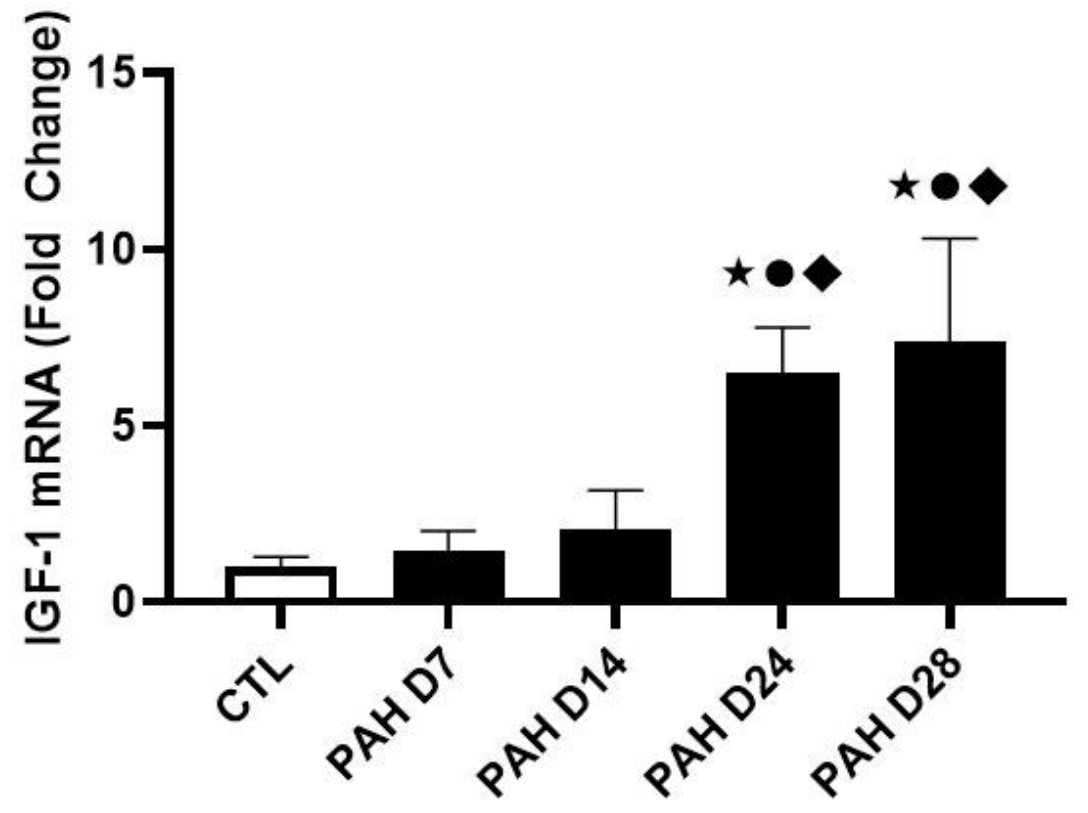

B.

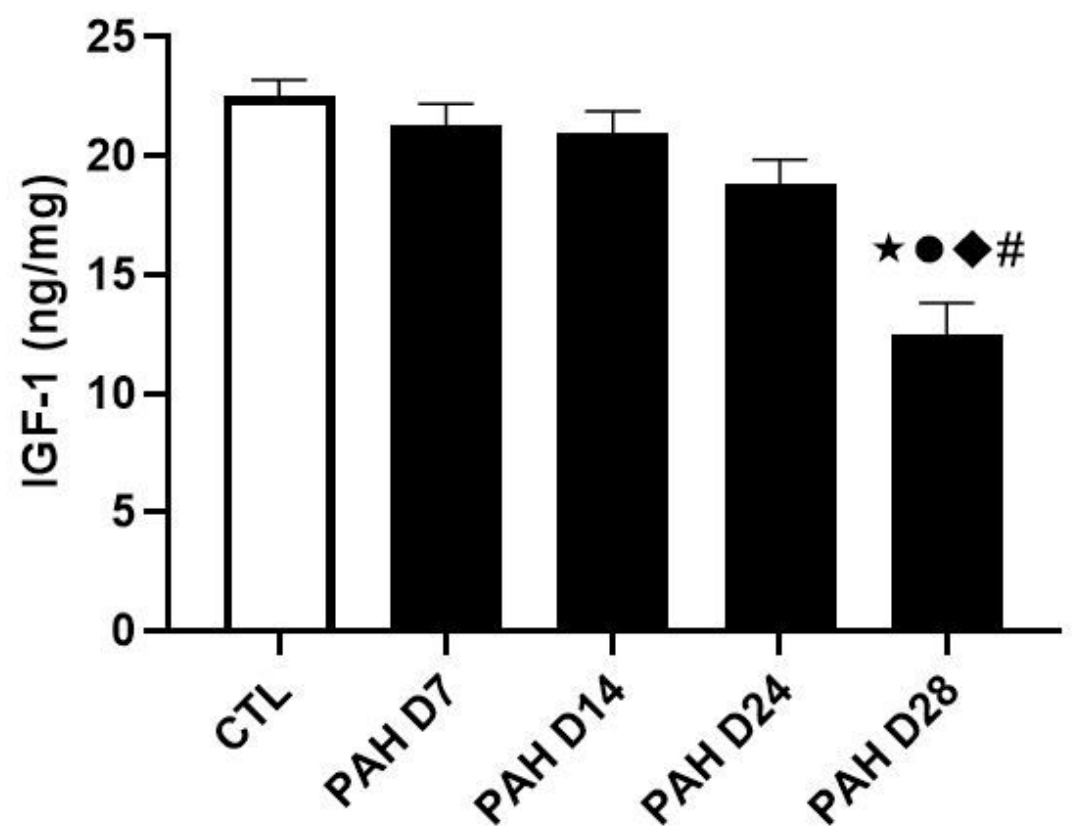

Figure 4 
IGF-1 mRNA and proteins levels in the RV free wall during the adaptive phase of PAH (A) Abundance of IGF-1 mRNA and (B) IGF-1 protein in the right ventricle of control (CTL) and pulmonary arterial

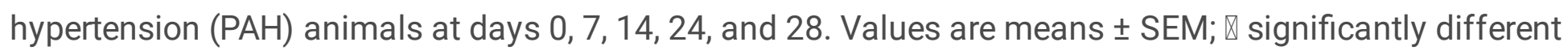
from CTL; $\otimes$ significantly different from day $7 \mathrm{PAH} ; \otimes$ significantly different from day $14 \mathrm{PAH}$; \# significantly different from day $24 \mathrm{PAH}$.

A.

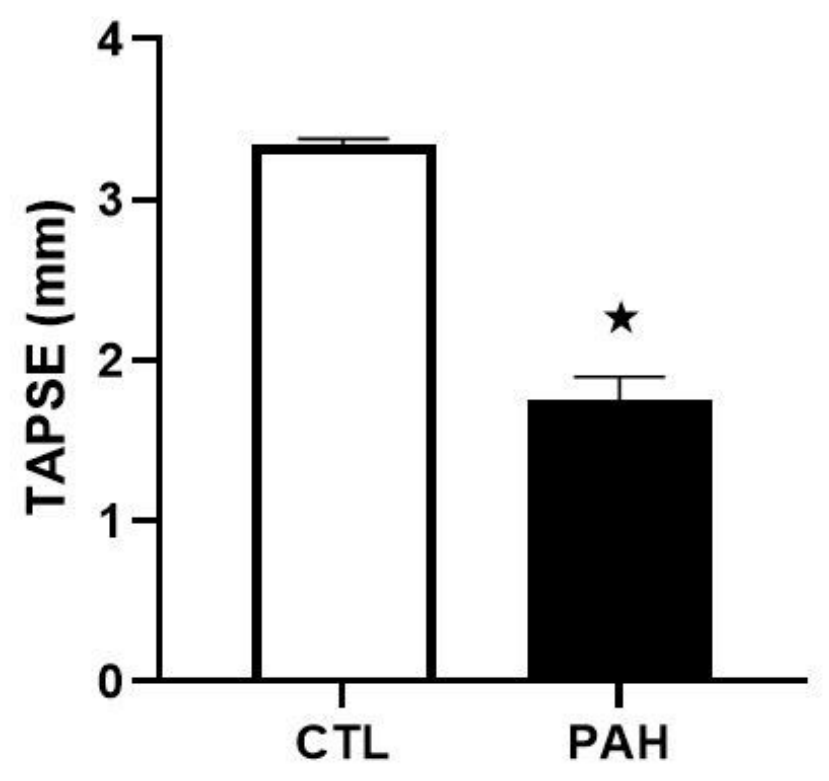

B.

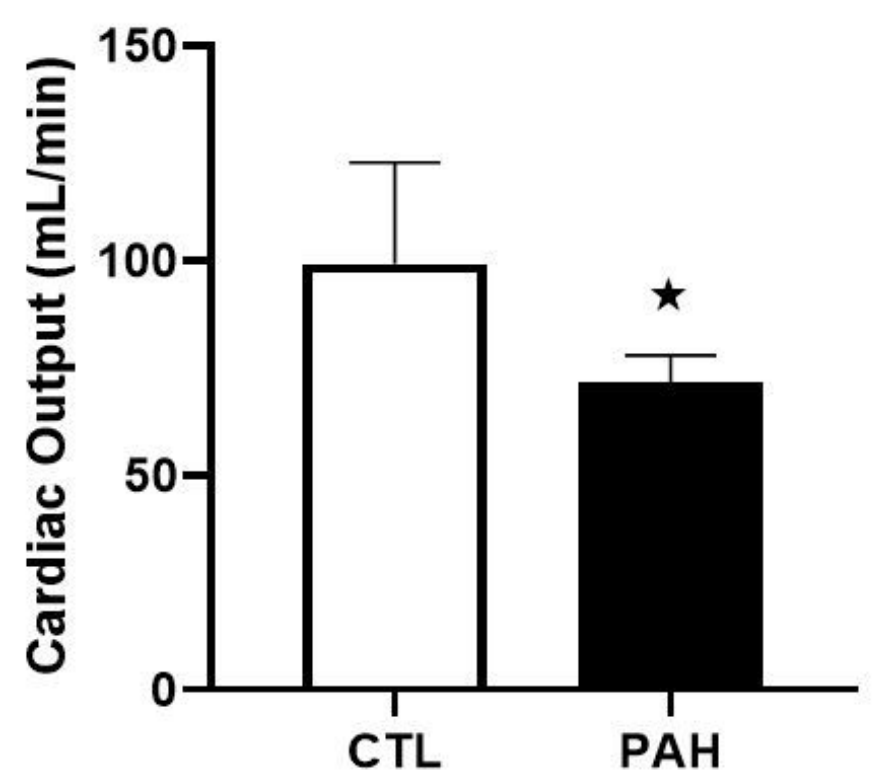

Figure 5 
Echocardiographic measurements of the RV in healthy and PAH animals (A) Values of TAPSE in normal controls (CTL) compared to that in pulmonary arterial hypertension (PAH) rats complicated by right heart failure (RHF). (B) Values of cardiac output (CO) in CTL animals compared to that in pulmonary arterial

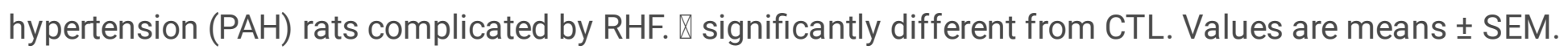

A.

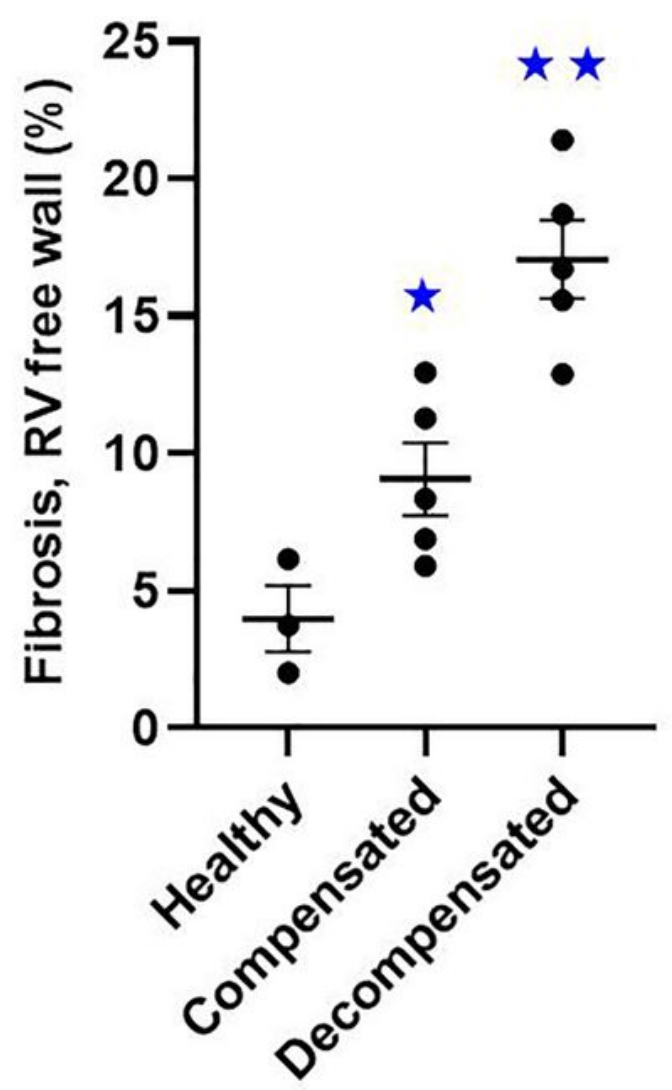

B.
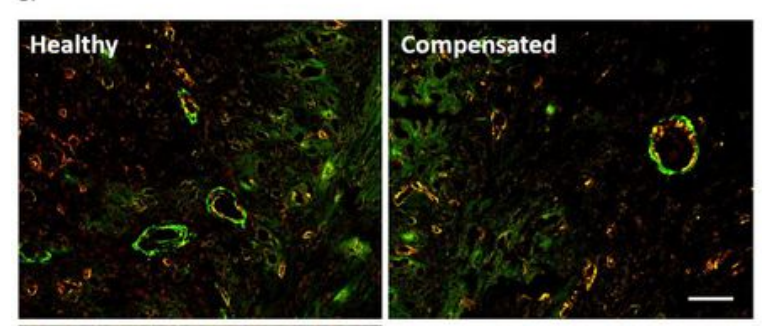

Decompensated
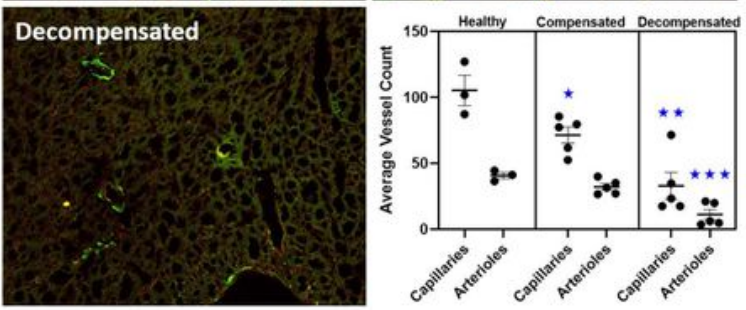

Figure 6 
Fibrosis and small vessel number measurements in the RV free wall (A) The individual values and average percent fibrosis of the RV free wall in CTL, compensated and decompensated rat hearts is shown. * indicates significant difference from CTL $(P<0.05)$. ** indicates significant difference from compensated hearts $(P<0.01)$. (B) Vascularity of $C T L$, compensated and decompensated PAH rat hearts is shown. Example images of capillary (green) and arteriole density (orange) in different stages of PAH are shown. Scale bar $=50 \mu \mathrm{m}$. Graphical representation of the average capillary and arteriole numbers per image for each animal is also demonstrated. * indicates significant difference from CTL $(P<0.05)$. ** indicates significant difference from compensated hearts $(P<0.05)$. ${ }^{* \star}$ indicates significant difference from compensated hearts $(P<0.01)$. Error bars indicate \pm SEM. 
A.

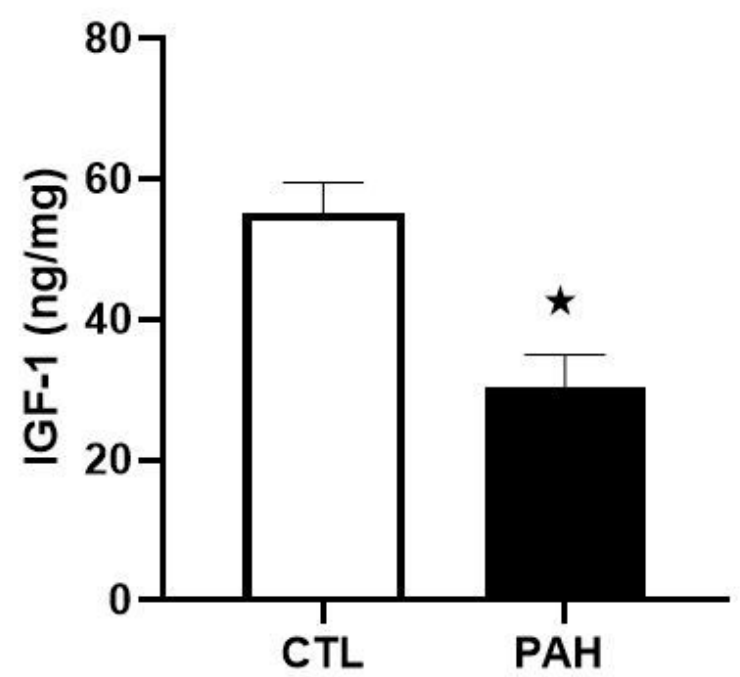

B.
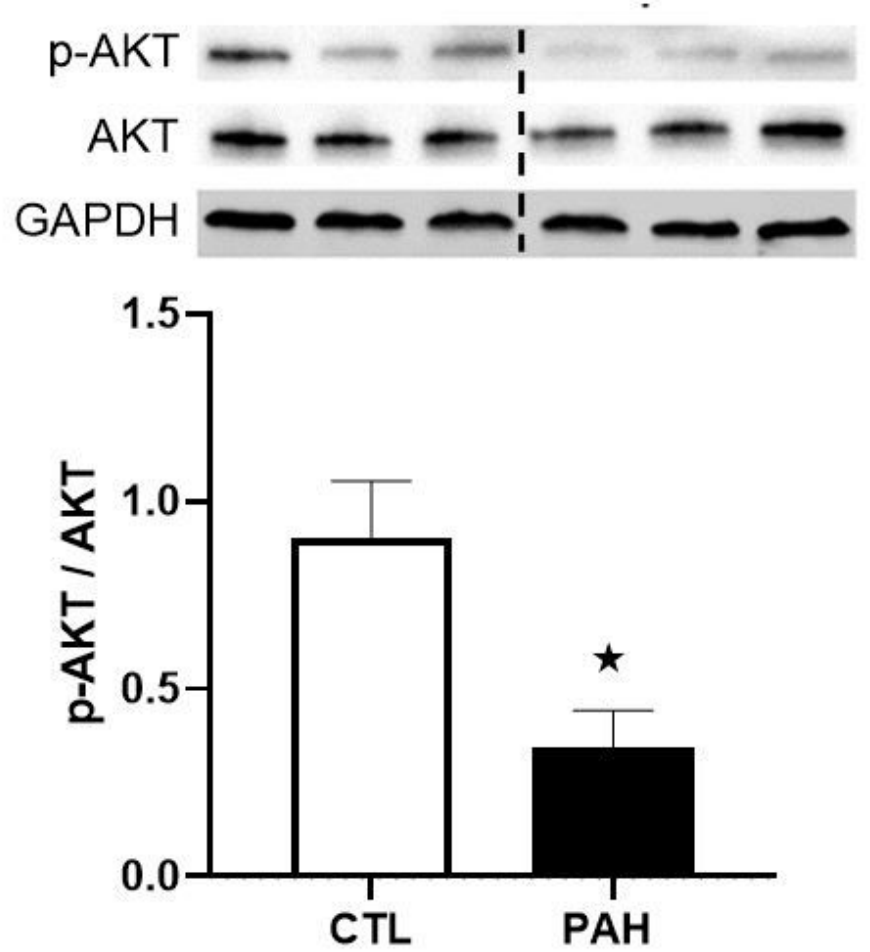

Figure 7

IGF-1 and AKT protein levels in the RV free wall complicated by RV failure (A) IGF-1 protein expression in the right ventricle $(\mathrm{RV})$ of control $(\mathrm{CTL})$ and pulmonary arterial hypertension $(\mathrm{PAH})$ rats complicated by right heart failure (RHF), expressed as $\mathrm{ng} / \mathrm{mg}$ protein. $\otimes$ significantly different from CTL. Values are means \pm SEM. (B) Phosphorylated p-Akt in the RV of control (CTL) and pulmonary arterial hypertension 
(PAH) rats complicated by right heart failure expressed as a \% of total Akt. $\otimes$ significantly different from CTL. Values are means \pm SEM.

A.

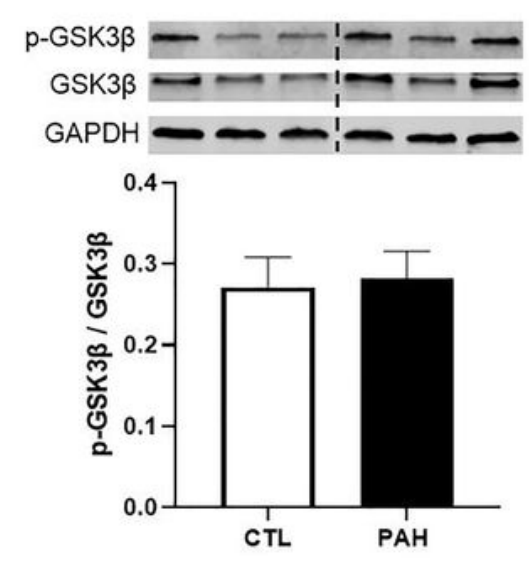

B.

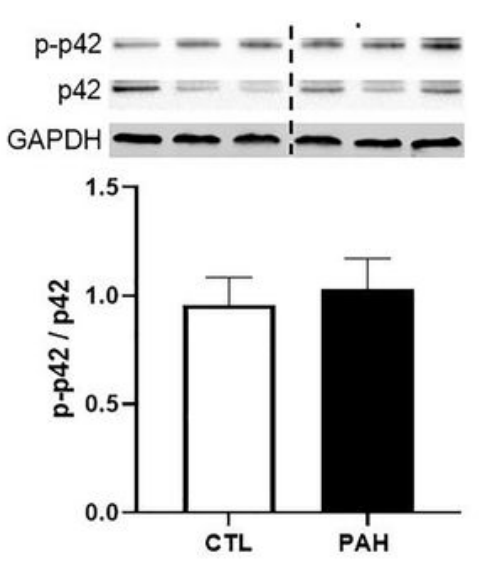

C.

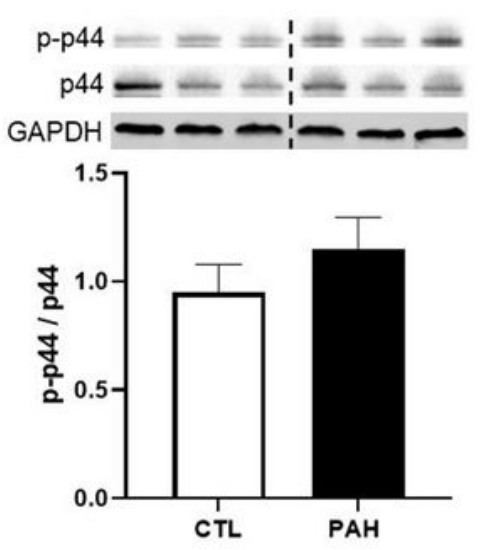

Figure 8

Phosphorylated and Total GSK3 $\beta$, p42, and p44 protein levels in the RV free wall (A) Phosphorylated pGSK3 $\beta$, (B) p-p42 and (C) p-p44 in the RV of control (CTL) and pulmonary arterial hypertension (PAH) rats complicated by right heart failure were expressed as a \% of total protein. Values are means \pm SEM. 
A.
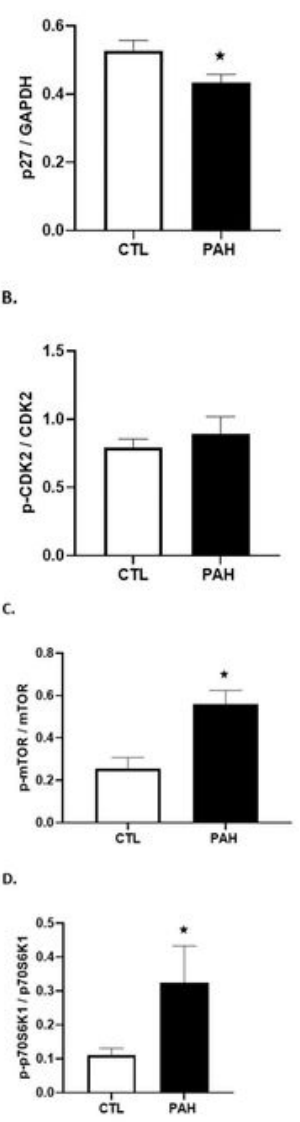

E.

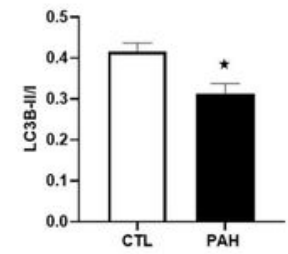

F.

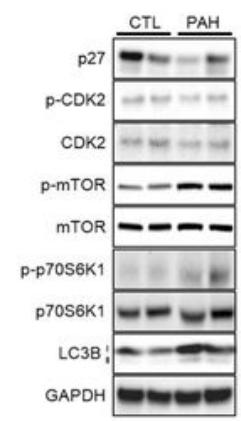

Figure 9

Phosphorylated and Total p27, CDK2, and P70S6K protein levels in the RV free wall Graphical representations of protein levels for (A) p27/GAPDH, (B) phosphorylated p-CDK2/CDK2, (C) p$\mathrm{mTOR} / \mathrm{mTOR}$ and (D) p-P70S6K/ P70S6K and (E) LCB3 I/II isoforms in the RV of control (CTL) and pulmonary arterial hypertension $(\mathrm{PAH})$ rats complicated by right heart failure. $\otimes$ significantly different 
from CTL. Values are means \pm SEM. (F) Examples of Western Blots for each of the proteins described above. 